\title{
The BIM2LCA Approach: An Industry Foundation Classes (IFC)-Based Interface to Integrate Life Cycle Assessment in Integral Planning
}

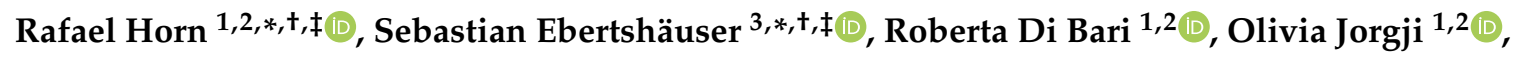 \\ René Traunspurger ${ }^{4}$ and Petra von Both ${ }^{3}$ \\ 1 Department Life Cycle Engineering, Fraunhofer Institute for Building Physics IBP, D-70563 Stuttgart, \\ Germany; roberta.di.bari@ibp.fraunhofer.de (R.D.B.); Olivia.jorgji@ibp.fraunhofer.de (O.J.) \\ 2 Institute for Acoustics and Building Physics (IABP), University of Stuttgart, D-70563 Stuttgart, Germany \\ 3 Institute for Building Lifecycle Management, Karlsruhe Institute of Technology (KIT), D-76131 Karlsruhe, \\ Germany; petra.vonboth@kit.edu \\ 4 German Sustainable Building Council (DGNB e.V.), D-70178 Stuttgart, Germany; r.traunspurger@dgnb.de \\ * Correspondence: rafael.horn@ibp.fraunhofer.de (R.H.); sebastian.ebertshaeuser@kit.edu (S.E.) \\ + These authors contributed equally to this work and are considered to be co-first authors. \\ $\ddagger$ Author to whom correspondence should be addressed.
}

Received: 26 June 2020; Accepted: 7 August 2020; Published: 13 August 2020

\begin{abstract}
An increasing degree of digitalization in construction planning offers significant potential for building life cycle assessment (LCA) to reduce access barriers, as well as the assessment effort itself. To realize the widespread application of LCA tools and their potential to effectively minimize life cycle impacts, an open approach is required that allows for flexible application of comprehensive LCA studies and early integration in planning processes. The authors present an approach for LCA integration in all phases of digital planning which aims at a DGNB (Deutsche Gesellschaft für nachhaltiges Bauen) certification based on the open Building Information Modeling (BIM) standard Industry Foundation Classes (IFC). The approach takes into account varying levels of development and resulting data availability during integral planning phases, as well as resulting LCA application contexts. It goes beyond existing strategies and allows one to consider both BIM and LCA software through a workflow based on a single data format. The assessment framework is operationalized through standardized interface development and technical realization following the information delivery manual (IDM) process standardized for IFC interfaces. The Extensible Markup Language (XML) schema, as a specific implementation for certification, provides the target system for LCA data requirements and is generalized to a planning phase specific IDM base table. The technical realization based on respective model view definitions and distributed data suggests a pathway to the standardization of LCA-IFC integration based on an open approach. The overall approach exemplarily applies to the "LERNZENTRUM" at the Karlsruhe Institute of Technology (KIT) campus. We conclude that an open BIM approach for LCA integration in model-based planning is feasible, but requires several adjustments in IFC, LCA, and planning practice. Adding a lifecycle element to the IFC to connect BIM and LCA provides comprehensive feedback for informed decision making based on environmental impact.
\end{abstract}

Keywords: life cycle assessment (LCA); Building Information Modeling (BIM); digital building LCA; exchange requirements; model view definition (MVD); information delivery manual (IDM); sustainable building assessment; level of development (LOD); Industry Foundation Classes (IFC) 


\section{Introduction}

Solving urgent and complex issues of sustainability in construction, at the building, as well as the urban level, requires a holistic, integrated approach. It needs to be practical and efficient enough to satisfy the quality requirements of sustainability experts and to be accepted by practitioners [1]. The building model and the resulting sustainability impact assessment of a system should not only consider individual processes or phases, such as operation. A holistic approach should also include the direct energy and the material flows, as well as their associated energy and environmental impacts over the entire life cycle of a system. The realization of such an approach implies the integration of a holistic evaluation accompanying planning and optimization of the planning object. The early-onset use of life cycle assessment (LCA) tools and integrated sustainable building assessment (SBA) provides an important basis for feedback on planning decisions at a conceptual level regarding their impact on the entire life cycle of a building, to ensure compliance with the targeted sustainability performance [2].

As current discussions show, the transformation of building practice is not achievable without technological innovations such as requirement-based and simulation-supported planning processes [3,4]. Therefore, the use and further development of such innovative digital technologies are essential prerequisites for the success of the building stock transition and critical enablers for sustainable development [4-6]. Despite the availability of IT-based life cycle assessment (LCA) assessment tools, there is no widespread use of SBA integration in planning and optimization processes or system-oriented sustainability evaluation systems of the so-called "second generation" [7]. Current discussions in the context of the Paris agreement, as well as the European Green Deal, aim to integrate LCA on a much broader scale $[4,8]$.

Guidelines for the public sector, such as the German "Guideline for Sustainable Building" or the German evaluation system "eBNB", the structural adjustments to the database "ÖKOBAUDAT", and the web-based software "eLCA", represent important steps toward sustainability in the area of public building projects [9]. However, what effect they can have on the entire construction sector remains unclear. An important prerequisite for the efficient implementation of such optimization processes in building planning is a consistent digital, and thus valid description of the building and building components, using a virtual building model. This must be able to depict the various constructive, functional, and technical relationships in different stages of concretization and, in turn, serve as a data base for simulation and evaluation tools. All relevant planning changes also efficiently update the accounting side. In practice, it is currently acknowledged that, particularly at the technical level, the non-standardized and inadequate connection of simulation and accounting tools to Building Information Modeling (BIM) tools and the resulting high expenditure of time for data acquisition and performing LCA calculations, counteract a greater penetration of the market [10]. The approaches that have been implemented in the field of LCA so far, focus on the assessment of buildings that have already been elaborated in great detail (here the specification is often used as input). They are only suitable to a very limited extent for accompanying use in the sense of an optimization tool that supports design and planning, especially in early conceptual planning phases. A finished product (planning) is evaluated retrospectively, instead of using the method in the alternative-oriented concept development with foresight. However, this is exactly where the greatest potential for optimization lies in terms of integral planning.

Linking SBA tools with BIM tools is seen as a key innovation for SBA mainstreaming and serves as a stimulus for the approach described in this article [7]. The improvement of BIM-based interfaces for the realization of energy and resource-optimized buildings assumes this point and integrates it into a holistic planning methodological process framework. For a target-oriented interface implementation, it is generally important to know the embedding context of a proposed data exchange. Hence, in order to support planners with an accompanying process application, the interface along with its embedding data exchange processes are located in a comprehensible phase model that depicts the life cycle of a building. This relates the general described processes to their given planning situations (and results 
in a better overall orientation). A system-oriented and interdisciplinary approach aims to achieve decisive benefits in solving complex planning problems related to environmental sustainability.

At an international level, several research groups are actively working on these issues with different solution approaches [11-15]. Wastiels and Decuypere provided a comprehensive classification scheme for strategies to combine BIM and LCA, highlighting the need for a consideration of application context in workflow choice [16]. Potrč Obrecht at al. applied this classification scheme to a comprehensive overview of literature on BIM and LCA integration, and identified three major issues that currently oppose widespread application, i.e., LCA methodology synchronization, information database conformity, and information exchange automation [17]. These points have been addressed by a subtask of the IEA Annex 72, dealing with building assessment workflows and tools with a focus on LCA and BIM [5].

The goal of this study is to contribute to the scientific discussion. We present an open approach and application to connect BIM and LCA throughout planning, in order to provide LCA from early design decision support to green building certification within one consistent, modular workflow. It makes use of the open BIM standard Industry Foundation Classes (IFC) in version 4.1 and complements this for comprehensive LCA integration. The core of the approach is the proposed life cycle element to structure LCA information in BIM environments. The approach was developed in the project "BIM-based integral planning", funded by the German BMWi, which aimed to increase the accompanying planning application density of life cycle assessments (LCAs) as part of integral planning, even in early conceptual planning phases. The main goal of the project is the implementation of a planning methodological and technological optimization of sustainable planning with a special focus on the integration of life cycle assessment tools and assessment systems in an integral planning process. An early integration of LCA tools and the resulting early optimization of building concepts enable the development of previously unattainable planning optimization potentials in terms of resource efficiency and sustainability. The focus is set to a generalized, cross-system approach that can map separately developed approaches (see, e.g., the certification systems of the BBSR (Bundesinstitut für Bau-, Stadt- und Raumforschung) and DGNB (Deutsche Gesellschaft für nachhaltiges Bauen), etc.) with the applicability of life cycle assessments during the planning phase throughout integral planning from the early conceptual planning phases (optimization instead of retrospective evaluation) to building completion, and potentially certification.

Following the introduction, in Section 2 we present the methodological background of the BIM2LCA approach and application based on the state-of-the-art. It presents the planning process framework, the considered technical interfaces, and the general connection of BIM and LCA. The section concludes with the BIM2LCA approach that presents the process the authors followed. In the Result section, we present the final BIM2LCA application, the underlying information demand specifications and implementation, as well as technical developments. The main elements are a comprehensive information demand table, a new "lifecycle" element for IFC integration, and a schema for LCA submission. We conclude with an exemplary case study on a wall element of a campus building in Karlsruhe. Finally, the presented results are discussed and an outlook on necessary next steps is provided.

\section{Research Background}

\subsection{Planning Process}

A systemic, holistic mindset stood at the root of the idea of integral planning that originated in the context of increasing ecological awareness in the course of the 1960s and 70s [18]. In the field of building design, integral planning is often required if a complex construction project is to be optimally implemented taking into account all aspects of building construction and building technology. With the aim of drastically reducing the energy consumption of buildings, this paradigm also established itself in standards, in Switzerland, for example, with the SIA performance model 95. Even if there is no 
unified definition of integral planning today, its application usually contains horizontal integration and vertical integration [19]. Horizontal integration aims to optimize the interaction of the subsystems of buildings (focus on system technology), and vertical integration takes into account environmental, economic, technical, functional, and social issues. These differ over the entire life cycle of the building with a focus on the aim of a sustainable building [20].

Here, throughout the planning and construction process, specialist planning has to be integrated by the main design process and share a common effort in order to achieve high quality of buildings. Because of specific needs of information structure within specialist software tools and missing uniform interfaces, up to now, model-based data, as derived from architects' coordination models as the base of specialist planning, mainly, have to be remodeled from scratch, with great effort. Adding to this, a corresponding susceptibility to errors and the time required for data input are found that limit the use of specialists' software and assessment as an accompanying tool, in the early planning phases, for optimizing the building design and examining variants of various basic concepts. In addition to enhancing the data flow with correspondingly optimized workflows on a technical level, the normalized integration of information structures, for input and result data on the side of the specialist planning facilitated by standardized open data formats, can also build a solid contractual basis. Thus, the original purpose and application workflow of specification standards, i.e., model view definition (MVD) in the norm-based framework of information delivery manuals (IDM), which are also elaborated on their technical side in the following section, has been extended in current praxis. From its native (technical) use case, to ensure quality of data interface implementations in software tools, this is now also implemented and, for example, already requested from German authorities in the context of client information requirements (Auftraggeberinformationsanforderungen, AIA) that are integrated in the treaty framework of respective BIM execution plans (BEP) [21,22]. Together, these newly established methods build a suitable process environment in which the (technical) implementation of solid model-based workflows among cooperating partners by means of BIM can be embedded [23]. Here, in a secured frame of self-defined structure, in terms of data quality through the a priori specification, all exchange processes in the project can contribute to a benefit thereof [22]. Currently, it can be observed that every discipline as part of the planning, construction, and operation of the built environment develops respective new workflows on data handling in the context of its digitization effort, and thus can be integrated with an overall model-based planning which helps to unlock the (full) potentials of BIM. As implied by the integral planning, the aim of process accompanying, iterative optimization of the digital planned object before its construction is at the core of these efforts at the process level [24-26]. Therefore, it achieves higher quality buildings regarding the specific aspects of the respective specialist discipline being integrated in the overall planning process, for example, building performance simulation (BPS), and also infrastructure planning, as well as regarding urban planning, i.e., the energy simulation of districts [22,27-29].

In the field of LCA, there is a need to carefully analyze how and when respective specialist planning information enter into the overall planning process. Despite a lack of well-documented practical experience, many approaches claim to harvest the benefit of integrating LCA in the "early" planning stages where it offers the most impact on the later building at the least cost. Here, studies show that due to not being properly defined, the term "early" seems to be applied ambiguously $[2,17,30]$. The point in time when the decision maker can make use of decision support is crucial as it determines the data setup regarding given information, as well as the LCA methods that can be employed together with the incorporated uncertainties [31]. Thus, many of today's approaches lack comparability with each other and also lack possibilities of scaling or transferability to other contexts [17]. The process accompanying approach presented in this paper, therefore, applies coarse LCA benchmarks on a building scale for initial decision support that successively decompose alongside the process into a more detailed LCA as information levels increase, for example, for types of building elements in order to address decisions on alternatives (Figure 1) [20,32]. In later planning stages, when the decisions with the highest environmental impact are determined, the approach considers the fine granularity of 
available data, as well as the most specific detailed LCA data on building components and materials which are already being used in practice for preparing specific building certification.

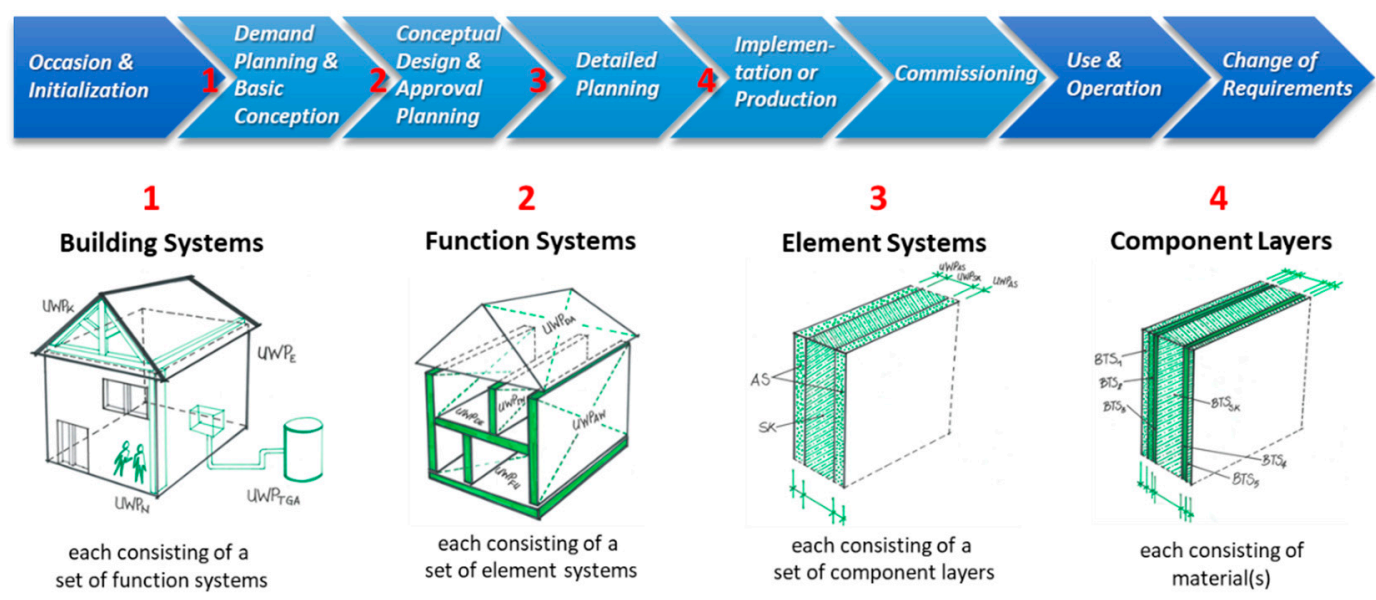

Figure 1. Phase-specific specification of the planning object as a reference system for the life cycle assessment (LCA). Based on [20,32,33].

\subsection{Technical Interfaces}

BIM is a widely applied workflow in the building sector providing the basis for digital architecture. It aims to enable the collaboration of all involved actors in the planning and design process, through providing accessibility for all, to one single digital building model.

Dealing with the increasing demand for information exchange in digital architecture, the necessity to transfer the planning process from a limited digital working environment (referred to as closed BIM) to an open BIM workflow is of great importance. In closed BIM, the planning actors work simultaneously on the same building model created in one (proprietary) data format, which is possible only when supported with programs by applications of one vendors' software family. Hence, these closed BIM workflow environments do not allow any flexibility for the relevant partners in using vendor independent software that, especially in terms of expert application, does not support proprietary data models of several vendors. Being advantageous when the same team of different planners originates in a single firm, it represents a challenge for the exchange of design concepts with external partners, especially in the case of public buildings [6]. The implied reluctance in implementing these closed BIM workflows can be observed well in the German market situation that traditionally consists of many smaller planning firms joining together differently on every project, and thus prefers open data exchange as the basis of collaboration [23,34].

The benefits of planning based on open BIM, are expressed in the flexibility of data, traffic with the application of neutral data formats such as IFC, BCF, COBie, CityGML, gbXML etc. that enable data transfer among programs of different vendors and, consequently, the export and import of data in adaptable and compliable data formats for each specific BIM software (i.e., NEMETSCHEK and GRAPHISOFT) [35,36].

On the basis of open product models, a methodology has been established in recent years under the term (open) BIM, in which the a priori specification of planning data (as well as their structures and qualities) enable standardized data exchange within the planning process [37]. Open BIM relates to and requires the collaboration of involved actors based on vendor neutral data-exchange formats determined by buildingSMART International [36]. A model-based working method is required to map consistently the planning object over the entire planning process in digital three-dimensional building models with stored semantics. The data to be exchanged among the partners within the scope of planning cooperation, such as specialist planning prepared by experts, then, is specified as a partial image of an overall model and the quality to be delivered is determined before the order is placed. The contractual basis for this is provided by the so-called client information requirements (AIA), 
which use references to the open model language IFC as the basis for the concrete specification of which data is to be supplied. In order to provide a formal framework for this specification, the information delivery manual, which originates from standardization work, is used with the formal IFC specification language model view definition (MVD) [22]. Initially, these IDMs were used to uniquely specify parts of the IFC that were required for the certification of IFC interface implementations in CAD platforms and authoring tools. With the increasing establishment of the BIM method, these methods and standards in the IFC environment play an increasingly important role in holistic data management.

The formal framework for creating an information delivery manual (IDM) is described in DIN EN ISO 29481-1 [38]. The standard stipulates that, for a particular business context, the specific cases of information exchange must be specified with an IDM in the given form. The last version of this standard from 2016 was supplemented and sharpened by further guidelines and templates in the context of its application in standardization and standardization work (see bsDE User Manual, IDM Word template, as well as VDI 2552 part 10.1 [39]). Therefore, a consistent set of tools is available for the standards-based specification of the basis of an IFC model view of a specific data exchange context. This set of tolls was also used in the research project which this article has been based.

An IDM serves to provide an unambiguous representation of the information to be exchanged against the background of a business context to be determined, such as the exchange between the coordinating architecture and a technical domain. After a preliminary definition of the scope of the IDM and the involved roles for the data exchange with the business context, a first main part of the project clarifies the exact process flow of the individual data transfers in the planning phase. Standards-based process diagrams using the diagram language Business Process Modeling Notation (BPMN) specify the exact data transfer points between role-based actors. Respectively in these points, the exchanged data is specified in tabular form in the second main section. A given table structure, first, requires the specification of a reference object, such as the building or component object, before successively nesting a characteristic concept or group, and then the requested characteristics of the data record to be exchanged (data drop). In addition to the natural language definition of the reference object, concept, or characteristic, each entry in the structured table must be marked to indicate whether it is mandatory or optional for the data exchange.

For the context of developing the IFC standard, different working groups apply the IDM methodology within the standardization body of buildingSMART for collecting information demands of different disciplines in the field of architecture, engineering, construction, and operation. Here, the intermediate goal is to provide suitable model view definitions (MVDs) that can serve the different observed data exchange scenarios. In a long-term perspective, the single views also contribute to the overall optimization of the IFC standard itself that evolves through the extension of description concepts to better suit its application in open BIM workflows. As a starting point for gathering information demands in the field of LCA, the approach presented in this paper, therefore, begins with the application of the IDM method. Then, this builds the base for a formalized extension of the latest IFC version in the framework of an MVD in order to profit from the latest developments in the standard such as the comprehensive HVAC part introduced in IFC Version 4. As different approaches for specifying and optimizing the application of the IDM methodology are currently under development, the IDM approach followed in the underlying research project and presented in Section 3.2 is based on the lessons learned from the other approaches and supplemented with (planning accompanying) aspects as required by the LCA application context $[8,12]$.

\subsection{Building Information Modeling (BIM) and Life Cycle Assessment (LCA)}

Life cycle assessment (LCA) is a methodology developed for analyzing possible environmental impacts associated with manufacturing and consumption of products and a central instrument for the quantitative assessment of the environmental quality of buildings. The principles and framework of the LCA methodology are defined in the ISO 14040 standard, whereas ISO 14044 determines the requirements and guidelines [40,41]. An LCA study includes four stages [41], as depicted in Figure 2. 
This is in the construction sector further concretized by the standards EN 15804 for the definition of core rules for sustainability assessment of construction products (PCRs) and DIN V 18599 for the assessment of building energy performance [42,43]. LCA models in the construction sector are usually highly modularized due to the hierarchical structure of buildings and make use of readymade Life Cycle Impact Assessment (LCIA) results that are publicly available for generic product groups and for specific products through Environmental Product Declarations (EPD) [44]. The methodology is contained in most certification systems for assessing sustainability, such as BREEAM, LEED, BNB, or DGNB, and the core of the emerging European Level(s) framework $[45,46]$. The continuous update of the LCA relevant norms and standards, points out the actualization of environmental indicators, especially the increasing requirements on product environmental footprint (PEF) [47]. The rise of requirements concerning the environmental performance, thus, leads to higher complexity of the LCA application and for full compatibility of these complex models, to planning practice [48]. Furthermore, this results in requirements to applied LCA data regarding updatability, consistence, flexibility and digital implementability that are not yet covered by existing construction LCA data [44]. Various SBA tools have been developed alongside the LCA methodology. Their main functions adhere to the evaluation of environmental performance for certification purposes, and some also address environmental comparison of design alternatives [49]. Often applied on completed planning status, the required information for LCA is currently rather unstructured and transferred manually into the LCA tools [7]. Due to the resulting susceptibility to errors and the time required for data input, life cycle assessment is rarely used as an accompanying tool for optimizing the building design in the early planning phases and for examining variants of various basic concepts [50]. Hence, neither can the function of an LCA accompanying planning cannot be fulfilled by these approaches, nor can they take advantage of the ongoing implementation of digital methods in the field of planning (e.g., BIM) and significantly reduce the needed effort for data acquisition [48].

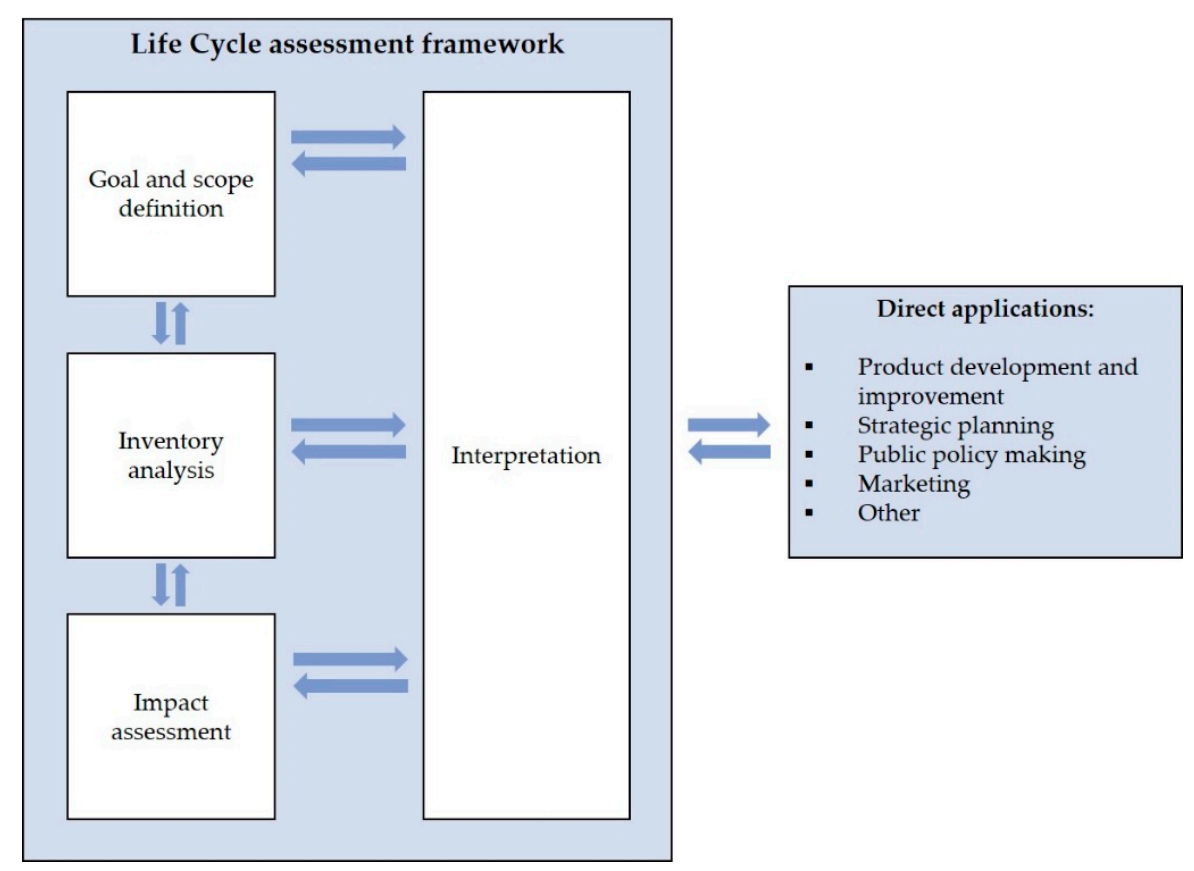

Figure 2. Stages of a life cycle assessment (LCA) according to [40].

In the last years, the integration of BIM and LCA has increasingly gained interest especially in research $[10,17,51]$. The integration of LCA with BIM is an ongoing process, which is evolving in parallel with the evolution of the LCA methodology and BIM advancement [52]. As such, this integration process is also inclined to become continuously more complex resulting in the need for standardization and harmonization of approaches. The application of standardized formats for data exchange enables 
interoperability throughout the planning and design process and aids the challenge of integrating LCA with BIM through space for implementing environmental impacts information in the overall data structure. The tendency of the new tools to integrate LCA information in the three-dimensional (3D) modeling process refers to the necessity from the building sector for available environmental assessment data. This issue needs to address the problems that arise due to ineffective information during data exchange or problems from insufficient data description of exchange requirements on the one hand, and, on the other hand, the need to extract environmental impact results throughout the entire planning and design process from the first stages [50].

The classification scheme provided by Wastiels and Decuypere presented five strategies for BIM-LCA integration. The two most frequently applied strategies were data provision for LCA through the extraction of a bill of quantity (BoQ) and the integration of LCA with BIM through plug-ins. However, both strategies offered significant challenges for comprehensive BIM-LCA integration. While the BoQ approach significantly reduces the effort for data acquisition, there is potential for error as the information is only linked indirectly. Furthermore, the information often times does not feed back to the modeler and decision support is lacking. Up to now, plug-in strategies do not consider specific data on the LCA side and are, thus, not feasible to meet the requirements of comprehensive LCA assessments [17]. Compared to these strategies, connecting the information demands directly to the data depiction concepts provided by BIM offers several fundamental advantages $[16,53]$. Whenever changes are made to certain planning information, the direct linking of LCA-specific data to a given quantity set results in a direct coupling. This approach is potentially more transparent and stable than the extraction of a BoQ and more flexible than plug-in strategies. Furthermore, with increasing concretization of the planned object during the planning process, BIM models facilitate depiction concepts to structure in one BIM object.

Most certification schemes foster the use of BIM for certification, but do not support BIM-based LCA submission [54]. In the context of a working group of the Association of German Engineers (Verein Deutscher Ingenieure, VDI), BNB and DGNB are, together with experts on BIM and LCA, actively working on a standardized interface for a BIM-based submission of LCA results [8]. While several SBA tools offer BIM-related services, they either represent the environmental impact in a simplified manner (e.g., IMPACT), or require very specialized open BIM data. In the first case, impacts are assigned to the area of a closed BIM environment, and can only be used in design-related planning statuses (mostly add-ons to proprietary CAD systems, such as the Rhino add-on of CAALA) [55]. In the second, often a complete remodeling of the BIM model is necessary. With respect to the digitalization of building information, the connection of data, in the context of LCA, with the data occurring in the process of planning implies the need for a common and unified data interface as a continuous database [17]. In ökobilanz-bau, this integration is carried out through an interface with Bim2Sim, while CAALA allows CAD and BIM integration as plug-in for Sketchup and Rhino models [55]. All existing SBA tools display environmental assessment results in certification-label templates, whereas eLCA and GENERIS $^{\circledR}$ allow the direct submission for certification [56,57].

The fifth strategy contains workflows with a fully transparent data handling by encapsulating LCA-specific data directly in the BIM object $[16,17]$. This integration type enables direct feedback of environmental impacts because only one data source contains all data. However, when realized through BIM objects, this information is not necessarily transparent or standardized. The BIM2LCA approach, presented in this paper, builds upon this integration type. By employing references to established external data sources, such as the data dictionary approach of buildingSMART, the approach extends these kind of integration types in order to address identified deficiency, for example, baring the risk of creating large and unresponsive files [16]. Adding to this, the full potential of the integration type is pursued by the BIM2LCA approach by addressing the information flow of the LCA-tool results and reintegrating them with the BIM model $[32,33]$. The implied workflow to connect BIM and LCA software bidirectionally is depicted in Figure 3. First, the planner creates the planned object in a BIM-based authoring tool (e.g., CAD). Then, the model is transferred to the LCA system, as a second 
step. This includes exporting the model as an Extensible Markup Language (XML) variant of the IFC standard (IFCXML) based on the LCA MVD using a BIM authoring system, server-based referencing (materials, constructions) and enrichment (integration of generic and predefined life cycle elements), and IFCXML import of the LCA system. In an optional third step, LCA experts can adjust, complement, and specify the basic LCA input according to LCA-related requirements within an LCA expert software. This step is realized within the web software GENERIS ${ }^{\circledR}$, which is the redevelopment of the web tool sbs online tool for building LCA by Fraunhofer IBP. Within the software, an IFCXML-based interface has been established which will be offered as a feature in future versions [56]. The fourth step, then, feeds back the LCA result into the BIM system through specification of results based on the use case requested in BIM, reintegration of LCA results in the IFCXML file, and import as well as result depiction in the BIM software.

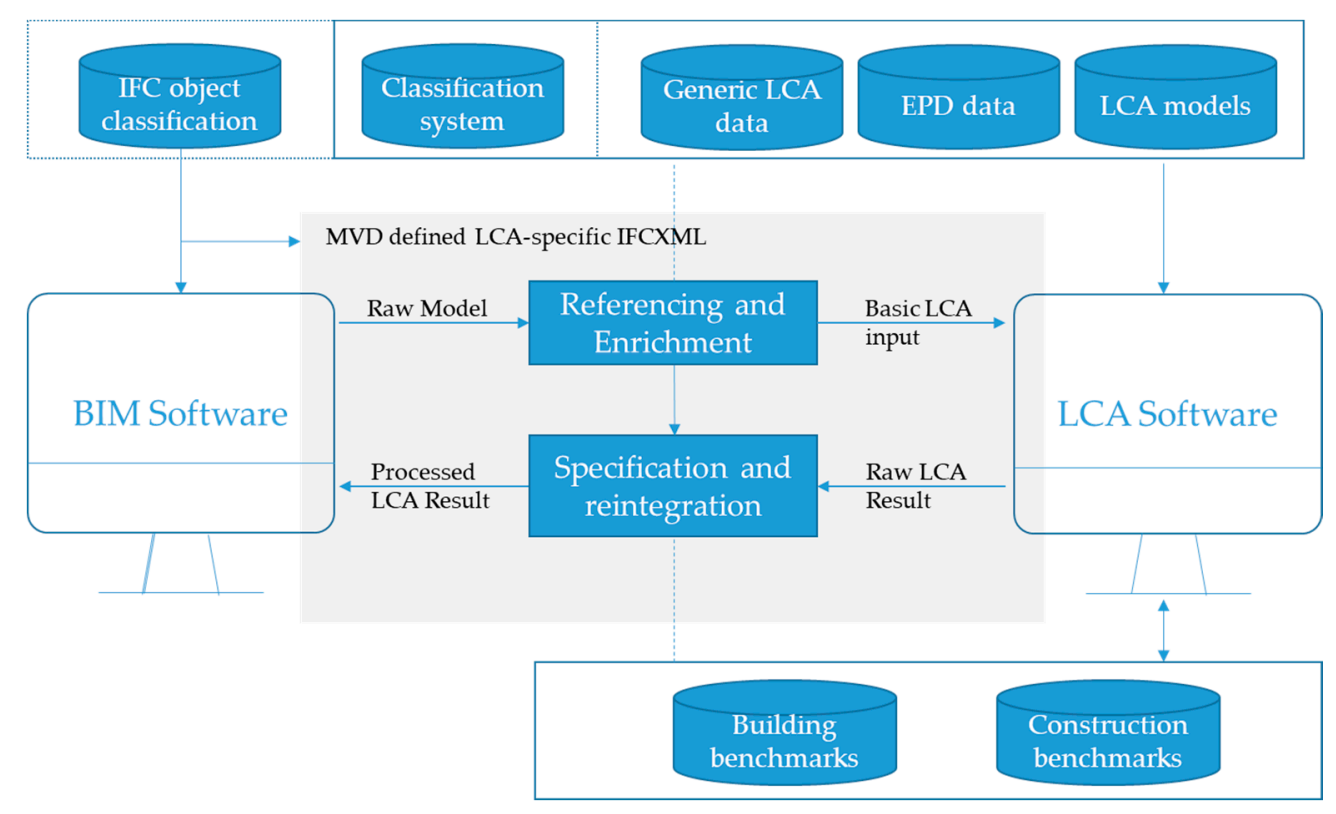

Figure 3. General workflow of the presented approach as an extension of the strategies defined by [16] Industry Foundation Classes (IFC)-based bidirectional Building Information Modeling (BIM)-LCA integration.

The approach, presented in this paper, suggests the integration of LCA with the BIM process through the creation of data requirements structure for environmental information exchange among BIM software and SBA tools, based on IFC standard (IFC4.1). The environmental information can be broken down into different levels of development (LODs), corresponding to the phases of integral planning (IP), through a hierarchical configuration of data in the IFCXML.

\subsection{The BIM2LCA Approach}

The framework of the research project, which forms the basis of this contribution, applied the following methods in a structured approach. A core building block for this approach is the conception of an information systematic that contains dimensions for different phases of building planning, construction, and use, as well as data granularities that provide a demand-oriented level of detail. At the level of technical integration (see Figure 4), the primary goal of the project is the implementation of an integrated planning process through normalized IFC interfaces for connecting LCA tools with BIM models (data input) and the preparation and configuration of the LCA result data for use in different sustainability rating systems (SBA). The developed information systematic (cf. Figure 1) resulted from a comprehensive process analysis regarding integral planning and LCA, which was conducted as a first step, is presented below in Section 3.1 and Figure 4. 


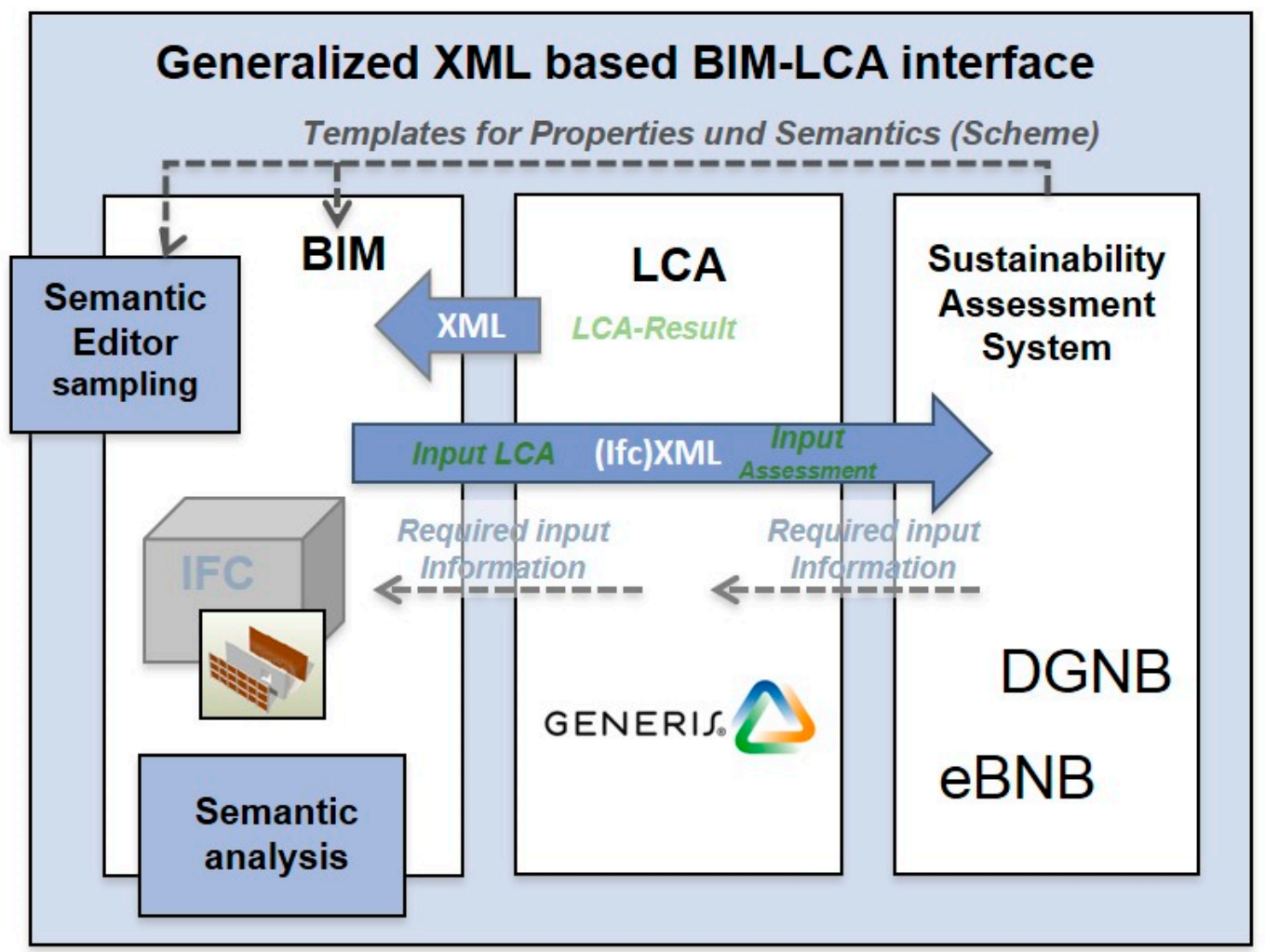

Figure 4. Concept and structure of the generalized interface of BIM, LCA, and sustainable building assessment (SBA) (BIM-LCA-SBA).

By matching corresponding LCA methods, as well as the respective (granularity of) input information demands of the process-accompanying concretization stages of the planned object, the information systematic, as shown in Figure 1, provides a fundamental reference system. This robustly connects the BIM planning and LCA-specific data in a transparent and replicable way. In order to realize a data interface from the conception of this information systematic, first, a clear specification of the exchange process is necessary to define the roles involved and their placement in the planning process. Because of these accurately pinned down points in the overall process, a data structure can be developed in order to enable a process accompanying, interconnected exchange throughout all the exchange points.

Following the norms of guidelines for these specification processes, as introduced in the previous section, the single data exchange processes should be depicted on behalf of open notations, as shown in Figure 5. In addition to the context of the exchange in the overall process, the sender and recipient, as well as the involved information (index of data drop), are thereby defined. A seamless application of data formats is suggested based on the addressed data drops in the process depictions throughout the planning process and is supported by this specification approach. The process-related information demands are uniformly described and are taken into account by the following steps of gathering LCA-related information demands, synchronizing them, and developing a suitable structure for depicting them in an interconnected way. 


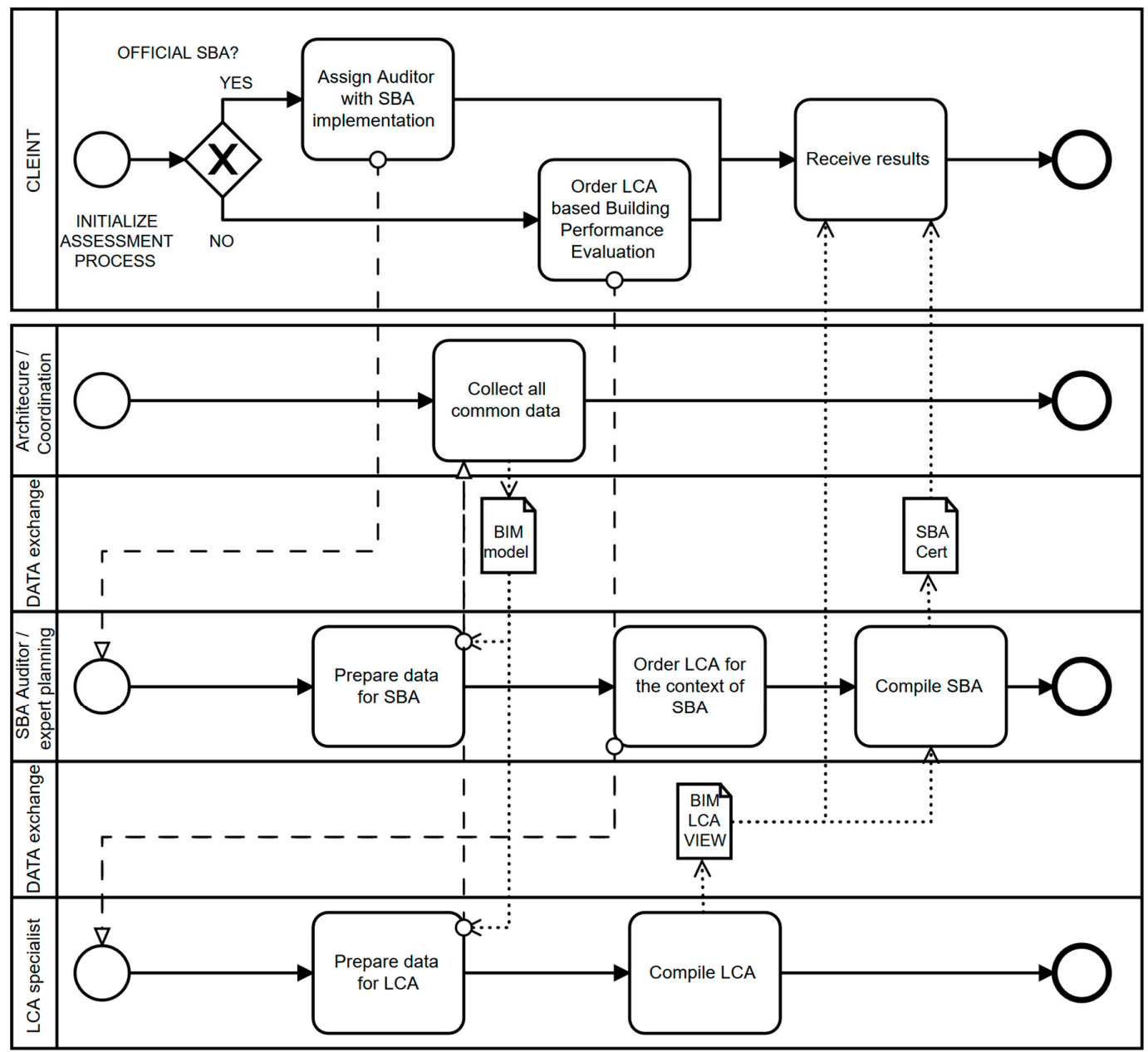

Figure 5. Sample of a process map of a data exchange scenario (an extension of [33]).

Consequently, the core of the data structuring approach is to connect building-related information of varying granularity with concrete norm-based building element-specific LCA data through benchmark-based demand side information management [32]. A two-layered specification process, thus, combines a flexible connection data object with a respective reference object in the building topology, for example, building, level building element, etc. (cf. Figure 1). The initial LCA focus on a data structure approach, as the first development step, enabled the connection of aggregated, as well as detailed building information, with respective (demand oriented) configurable expert information related to LCA. For every exchange scenario, this could be evaluated and optimized. In the second development step, the identified and referenced data structures were normalized on behalf of the open IFC standard. Here, common building information and aggregates already in use during planning (e.g., the quantities of physical building elements incorporated in an LCA-centred data structuring approach) are matched and respective IFC-based entities are specified. For the other parts of the flexible data object, corresponding entities for IFC are defined. By extending the standard, current software applications are required to handle entities that are not (yet) part of the IFC. Thus, simplified specifications on the basis of IFC's flexible property depiction concept are also developed as an intermediate alternative for the long-term targeted enhancement of the IFC standard. In order to support multiple application scenarios, the normalized BIM with LCA interface approach is embedded within a norm-based data matching context that involves two stages of external data. Following the data dictionary methodology, which can be connected to a BIM model via reference objects, a material classification is provided as a uniform referential backbone for the connected LCA and planning data and is realized as a first distributed dataset via web services. In addition to being able to fully depict 
the LCA data in a local IFC model, a second distributed data catalogue provides LCA-specific contents that can be referenced in the BIM model which are either replicate, for example, benchmark data, or relate to certain common construction types or redundant occurrences of preconfigured expert data for specific layouts. On the most detailed depiction stage (see right hand side in Figure 1) the approach provides direct links to LCA database objects, for example, OEKOBAUDAT, items in order to have data models that comply with identified needs. These kinds of enhanced IFC models use model-based LCA data in official SBA procedures, for example, in the targeted DGNB SBA process, and thereby significantly reduce the involved effort in data handling.

\section{Results}

\subsection{The BIM2LCA Application}

In order to pursue the implementation of a methodological and technological optimization for sustainability-oriented planning, the research project BIM2LCA4IP sets a focus on the accompanying process integration of LCA and SBA tools with the BIM-based planning process. An early integration of LCA tools into the planning process and the optimization of building concepts enables more optimization potential with regard to resource efficiency and sustainability, which further approaches could not always attain. Therefore, at the core of this approach is the structuring of information demanded by respective tools to deliver tailored LCA solutions for the planned object along the different planning phases, as depicted in Figure 6.

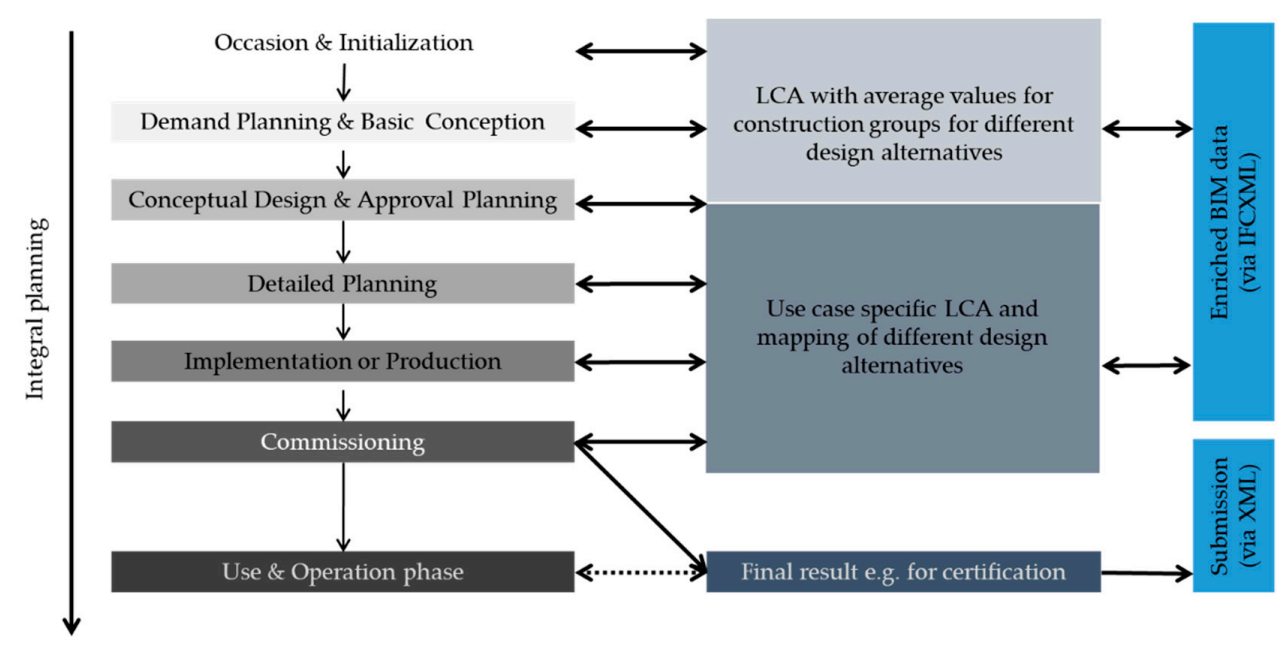

Figure 6. Different LCA solution stages of the approach connected to planning phases.

An integrated approach with two layers achieves the following abovementioned goals: (1) a higher-level methodological process level (phase model integral planning) and (2) a technical level with the development of a generalized BIM interface (that wraps the previously mentioned core). Analysis and evaluation processes are located in a knowledge-based process and phase model developed for the higher-level planning process on the first layer. They serve as process pilot for the application of integral planning (Figure 1) [20]. This phase model forms the structural framework for the conception of a web-based knowledge platform, which will be made available online at the end of the project [12]. It provides experience-based knowledge about relevant thematic aspects of sustainable planning and sustainability requirements to be addressed in each planning phase. In addition to this, the platform indicates when the initiation of evaluations and analyses can generate the greatest added planning value.

On the basis of such recommendations, all actors within the planning process receive further support on modeling quality during the creation and the update of the project-related BIM model. Lastly, the platform ensures methodological consistency across the planning process through coarse 
reference values. These values are, for example, for early stage benchmarks based on data gathered on already assessed buildings, more specifically element-related area and volume-based reference values provided for the first variations in (initial) design stages, and finally, well connected to these demands and building targets, facilities for detailed component descriptions (Figure 1).

The information systematic developed at the core of a targeted data interface between the BIM-based planning and a process accompanying LCA combines all information demands continuously through the process phases and in the demand-oriented granularity on different levels of detail. In the early stages of building information, for example, aforementioned benchmark-based target LCA values refer to highly aggregated levels, i.e., so-called building systems (Figure 1, left side). The initial design parameters and the continued concretization of the planned object, for example, variations of the core construction type based on sets of archetypes, refer successively to the decomposed systems, here called functional and the more detailed element system. The most detailed stage in the information systematic finally represents the information needed as input in an SBA framework for a LCA. Hence, it is equivalent to the so-called as-built data on the realized construction. From the LCA perspective, for all stages of the systematic process, there are interrelations among the underlying methods as follows:

- fine granular specific material-based LCA;

- $\quad$ aggregated building element LCA types;

- coarse construction LCA archetype;

- benchmark-based building LCA.

The thereof derived data interface needs to enable consistent input from LCA tools and also principally supports continuous and comprehensible data flow regarding the environmental impact throughout the process. In order to highlight features of the developed IFC-based interface in this paper, in this section, we detail its common (process independent) workflow as described by the underlying kind of approach above (Figure 3) with the background of a concrete SBA use case, and present a case study thereof in the next section. Figure 7 shows the adapted strategy of connecting the BIM and LCA software tools, as well as incorporated external (distributed) databases that serve this use case, which occurs at the end of the planning phase. For the previously mentioned general workflow, the four instances of the successively enhanced BIM model in the IFCXML format in the case of the SBA certification process are depicted together with the respective steps. The final model-based LCA results are prepared as needed for the submission of LCA data in the framework of a DGNB certificate application.

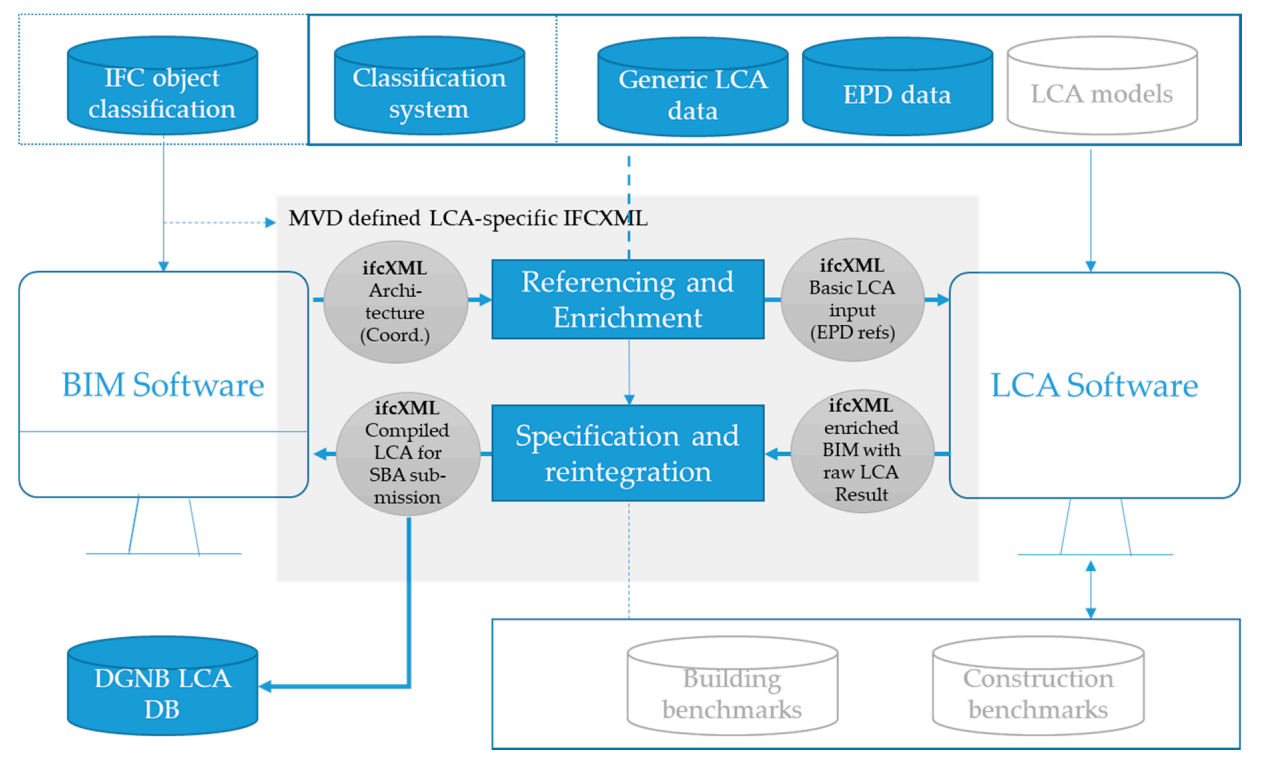

Figure 7. IFC-based bidirectional BIM-LCA integration strategy specified for the applied use case. 
To demonstrate the overall practicability of the process-overarching information systematic that was developed within the research project, including the use case presented in this paper, three spotlights are set on the process together with the definition of respective data exchange scenarios. To support a heterogeneous project configuration in the current practice, a frame with different roles has been generally defined as common background. This is allocated, in a business context, as the initial steps of the application which are introduced below with the IDM methodology. In such a context, shown as example process in Figure 5, the builder or client, who needs guidance or decision support in the field of sustainable building and LCA, works together with an advisor, namely an SBA auditor, with expertise in such fields.

With regard to model-based planning, an architect is responsible for the coordination of planning information throughout the process, and therefore serves as the main data provider. Experts in structural analysis or energy efficiency provide further detailed information coming from their specific model. They are not detailed in the process map, since the architect ideally has already merged their expert information in the coordination views of the central BIM model. The information that is relevant for the LCA is selected from the architect in order to avoid overlaps, by focusing only on quantities provided by the final architecture model. When the process map is applied in practice, all processes regarding the data handover to the coordination view from the single disciplines, for example, structural planning, that are defined in respective working groups of the standardization initiatives, of course have to be taken into consideration. Regardless of all roles that are carried out by single persons or combined in different ways, the depicted tasks in the exchange scenario describe the context of information demand and flow between a sender and a recipient at a certain point in the process (swim lanes of data exchange in Figure 5). In addition to the already published exchange scenarios in the early project initialization and planning stages, the baseline scenario of this work refers to the process of the LCA compilation in the framework of an SBA [28]. This implies that the information demands underlying the flowingly presented interface (development) focus on the later planning stages, where detailed information on the construction is available. Hence, the context of the data exchange exists on the right side of the information systematic, as shown in Figure 1 and refers to the stage called component layer. The full process map depicting the exchange scenario as the first process related part of the IDM is available in Supplementary Material 1.

\subsection{Information Demand Specification}

Through the immediate project information exchange enabled by open BIM workflow, a neutral IFC can integrate environmental information coming from the LCA model. Especially in the field of BIM-LCA, this seems to be particularly advantageous. For instance, when the LCA calculation is carried out based on a defined BIM model, the information is directly extracted in a standardized exchange format to a sustainability building assessment (SBA) tool. A comparison with other approaches shows that this approach provides more accurate environmental assessment results. Moreover, a single format such as IFC and Extensible Markup Language (XML) can avoid manual re-entry in the SBA tool [58].

The created IDM represents the guidelines for redaction of the information exchange document, which in this case is an XML file. As for every XML, a data structure (i.e., as defined by a XSD file, see Section 3.3) is required. Lastly, the information included in the XML is sent to the SBA tool, which gets the input data for the environmental assessment. Then, the SBA tool can back up the LCA results and compile the XML. The final document can include entries for the building certification submission (Figure 7).

The BIM-LCA interface has been tested in GENERIS ${ }^{\circledR}$ and is under further development for final implementation in the web-based tool. It is necessary to underline that the test refers to a full BIM-LCA, where the building model is able to provide comprehensive and accurate building information. The more the level is defined, the more the information is detailed and the LCA results are accurate. 
Next, we report on the structure of the IDM with some examples. Additionally, a comprehensive IDM table is available in Supplementary Material 2. In the IDM, each object type refers to one of the aforementioned concretization levels and presents several characteristics. When the information is particularly complex, several specifications are grouped (here called characteristics) into a specific concept. For each characteristic, the IDM table provides s description, examples, sources, and all required documentation. Depending on the software development process and from the IFC format, each object can be further specified and enriched by details and, consequently, by further characteristics. For each planning phase (see Section 3.1), the characteristic is classified as existing or new, and in this case, as mandatory (must be entered) or facultative (can be entered).

In this sense, a classification of characteristics occurs. A characteristic can be classified as

- Entered directly into the IFC (A);

- Indirectly as further enrichment of IFC (B);

- If the characteristic cannot be found in IFC and represents further information, it is classified as mandatory $(C)$;

- Or optional (D).

Examples of directly submitted information are the geometrical features of a building, gross volume, surfaces, and all architectural characteristics (Class A). Meanwhile, LCA and life cycle costing (LCC) databases can enrich the IFC and, consequently, the realized BIM model (Class B). Characteristics of the life cycle phases of the LCA, in which the environmental impacts of the project's levels are calculated, are necessary information (Class $\mathrm{C}$ ) however, for instance, the observation period of the analysis can be omitted, whereas a standard 50 years' observation time can be considered. In addition to this, results coming from LCA and LCC (E) and supplementary information without direct use in the LCA (F) are considered.

According to the realized IDM, Figure 8 shows the increasing information requirements over the building planning process. While the mandatory assignment increases, especially between the second (preliminary design) and the third phase (final design), the optional assignment decreases. Overall, the final design and the implementation planning ( $\mathrm{PH} 4)$ do not present wide variations. During the implementation and certification (PH1), the increasing demand of entries is due to LCA results and further mandatory specifications. The different input options represent potential data sources, as well as different approaches to deal with the information elements. The underlying calculation is documented in Supplementary Material 2 along with the underlying information requirements.

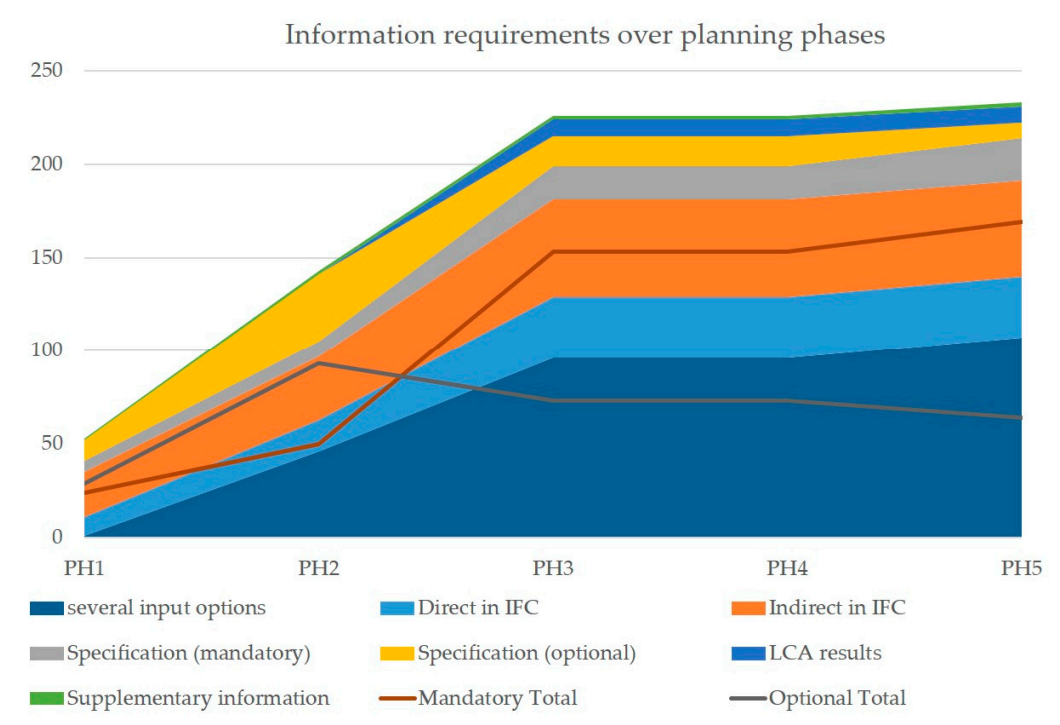

Figure 8. Number and type of information elements during planning phases given in the presented information delivery manual (IDM). 
As reported by [53], a comprehensive LCA is possible with the help of SBA tool only after the collection of all necessary information regarding materials, amounts, processes, i.e., with the completion of the final design (full BIM LCA) and an eventual submission of the project for building certification. Meanwhile, the provision of environmental information is more challenging during the early decision-making process and early building design. However, as reported by Di Bari, through an opposite procedure, results coming from previous building or building parts' analyses can be collected in a database, in order to derive from praxis (bottom-up) benchmarks for decision making [5]. In this sense, the final developed BIM-LCA interface, with the upload of several projects and the enrichment of the databases, enables better data organization and more automatized derivation of benchmarks.

Main objects of IDM match the abovementioned level of definitions. In additions to this specific LCA and DGNB certification, the following related objects are established:

The Project object presents all metadata of building under assessment, i.e., contextual information (title, description, and identification) and settings for LCA (database, functional units, functional equivalent, etc.), LCC (cost database, version, etc.), and certification (certification type, characteristic values according to energy balance, LCA submitted results, etc.).

The Certification results object reports results coming from the building certification, benchmarks for the assessment, and all necessary metadata for DGNB certification.

The Building (construction object) object presents all general information of the building under assessment, for example, building type, description, indication of the direction to which the building is oriented.

The Construction object relates to a general, both multilayer, component-based and one-piece components. Hence, descriptive (name, construction classification type, and classification) and quantitative information (quantity, unit, and construction lifespan) are reported.

The Part object depicts the individual parts of a component not further decomposed (or the component itself not further decomposed). Here, as well, general (name and ID) and quantitative information are reported.

The Material object relates to the individual layer and its general and quantitative information.

Objects that represent the four established levels of definitions present similar hierarchy and characteristics. In this regard, characteristics, such as dynamic quantity and LCA results, can be found. Dynamic quantities enable dynamic LCA and LCC analyses. The grouped results of each material, part, construction, and the whole building are reported in the LCA and LCC results.

Furthermore, own objects contain information and database links and are the referenced objects from the various LCA-relevant characteristics.

The technical equipment and building installations can be partially described by the previous objects only from a constructive point-of-view. Information belonging to, e.g., the building operational energy performance, energy sources, and systems specifications are collected in two main objects. The object technical system contains information on the specific final energy demand values by energy source, based on the net floor area. The object "technical component" collects information of several parts of the installation systems (e.g., burner, radiator, heat pump belonging to the building heating system).

\subsection{Implementation and Technical Development}

As already mentioned, information exchange occurs through an XML data format. In the first stage, an XSD file is realized (see Supplementary Material 3). Here, the information is organized under a precise hierarchy. The choice of XSD data structure complies with the employed web-based SBA tool GENERIS $^{\circledR}$ and takes into account the requirements based on the DGNB building certification system. The XSD specifies the data required for DGNB certification and XML-based submissions based on this XSD and the currently developed documentation are fully accepted as the LCA submission. As the DGNB system credits LCA integration in the early design stages, the planning phase consideration 
in the XSD allows it to also submit conform XML documents to prove early planning integration of LCA. In the XSD, the characteristics defined in IDM are converted into single or complex elements. According to the provided documentation, elements can be classified into different formats or subjected to restrictions in order to guarantee results consistency and correctness of entries.

The XSD consists of the following two main complex type elements: (1) LCA data and (2) DGNB data. In the LCA data, the environmental assessment settings are provided (Figure 9) and include the following:

- The used environmental databases (name, region version, and web reference of database);

- Functional units (defined by their short name, a description, quantity, and unit);

- Language and region of the applied data sources;

- LCA type, i.e., considered standards, and LCA approach. With the latter, the user defines whether he is carrying out a scenario analysis, dynamic, or probabilistic LCA (boolean elements). If those are activated, the user index each scenario or dynamic value.;

- Indicators, which represent the environmental indicators with their name, a description, the standard and further references, their exchange direction, and unit.

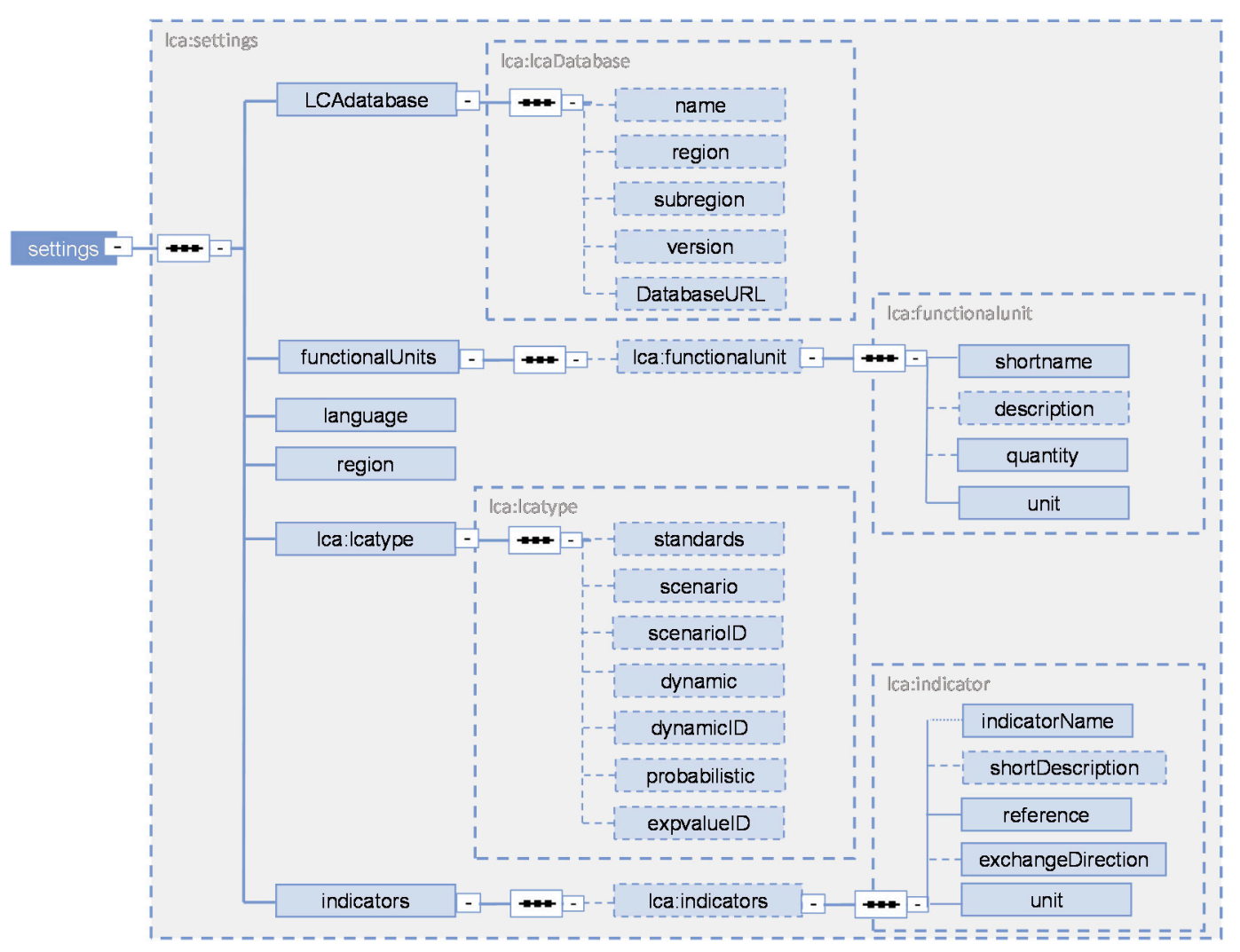

Figure 9. LCA settings in the structure of the life cycle element. Elements with solid lines are considered mandatory and dashed lines represent optional entries.

Other elements of the LCA data collect relevant information for the environmental assessment of a project, building constructions and parts. Each of these elements is, in turn, a complex type element made by a set with all general and identification specification; a quantity set (such as material quantities and construction surface area), and lastly, an LCA data element (complex type, <lca:lcdata $>$ ) as depicted in Figure 10. Within it, we identify the following:

- $\quad$ Life cycle phase $(<\mathrm{lcphase}>)$, the information is here restricted to life cycle module of EN15804 (A1-A3, B4, B6, C, and D); 
- Quantity (<Quantity $>)$, the amount of each considered element (e.g., $\mathrm{m}^{2}$ construction) and the unit $(<$ Unit $>$ );

- The considered environmental indicators (<indicators $>$ ), where the user assigns indicators name according to, for example, PEF indicators (EN15898).

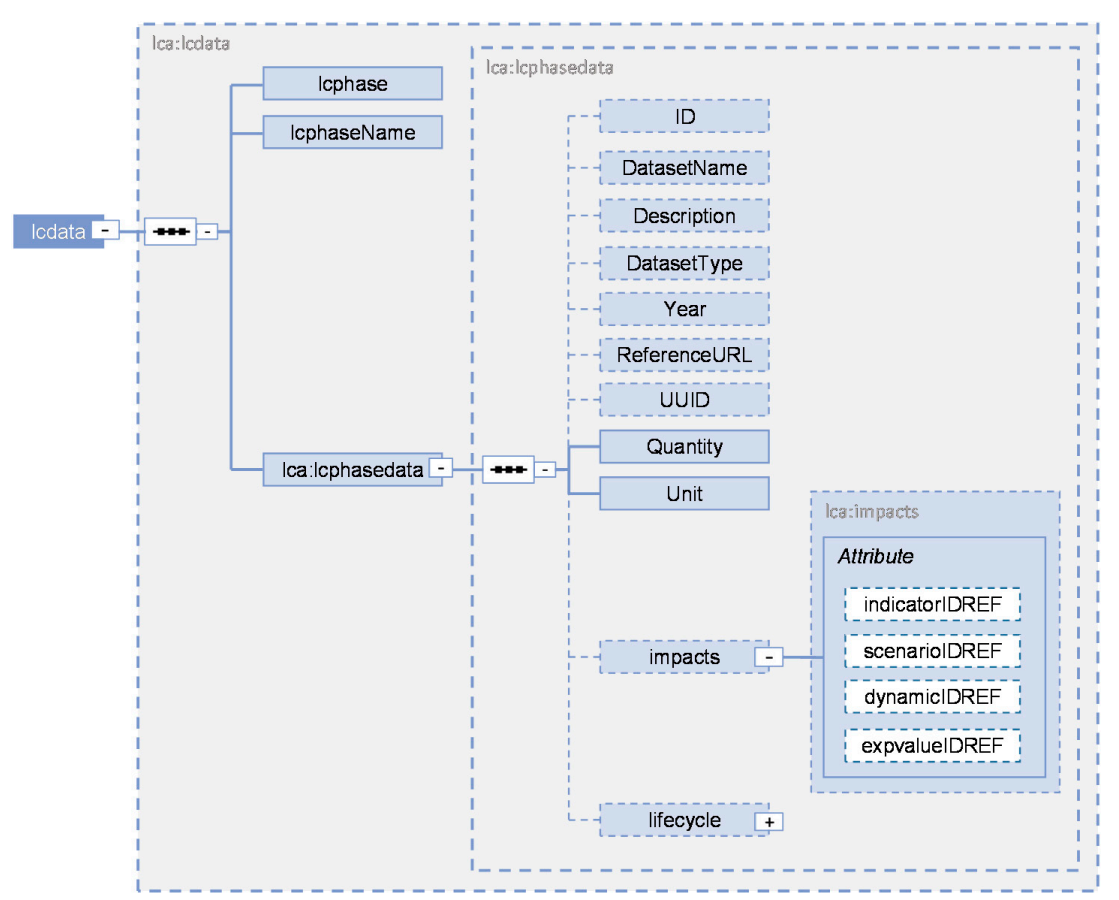

Figure 10. Structure of the life cycle element. Elements with solid lines are considered mandatory and dashed lines represent optional entries.

The life cycle elements (<lifecycle $>$ ) is present in each level (project, construction, and part). This special feature enables the collection of comprehensive LCA results and a grouping for each level of definition (full BIM analyses), as well as the eventual environmental benchmarks for case studies, for which there is not an extensive data collection.

Lastly, the $<$ DGNB data $>$ element refers to the certification results object of the IDM (see previous section) together with its related own objects.

The presented entities of the LCA-focused XML schema build the base for the normalization into the open BIM standard IFC. For the connection element $<$ lifecycle $>$ at the core of the schema, as well as the technical concept, to externalize (optionally) certain exchanged data in the defined interface into web-based data dictionary, the respective developments are exemplarily shown.

In Figure 2, the different informative parts that are necessary within an assessment framework in order to analyze a building or any of its parts are depicted. In addition to the rather LCA-specific fields of specifying respective goals and assessing impacts, as well as the interpretation, a great common ground of information demand is shared with the planning side in the inventory analysis step. The same information needs as the LCA input can be found in the process of quantity take off, for example, in the context of cost estimation or materialization. Therefore, depiction of quantities incorporated in the <lifecycle> element can be fully realized with the according IfcQuantity concept. Following this initial step of normalization, all parts of the structured data object are re-factored and where possible directly matched with respective depiction concepts in IFC. This matching is achieved by extending the above-described neutral collection of information demands within the framework of an IDM with further columns to specify the corresponding IFC entities. Due to the flexible nature of the IFC, the general part of the <lifecycle> element can be accomplished rather easily according to its targeted aggregation level within the topology of a building. Thus, all spatial IFC elements (IfCSite, 
IfcBuilding, IfcSpace, etc.) as well as the physical elements (IfcBuildingElement and derivations hereof) can be extended with the dataset encapsulated in this LCA-specific object. By placing the dataset into the topology, the previously mentioned quantities are also already specified through this given context. For instance, if a lifecycle dataset is placed on a decomposed wall element (e.g., a layer object instead of the wall object itself), it implies that the also needed quantities have to be gathered from the geometrical representation object or alphanumerical property (e.g., material layer set) data of the wall layer. For the encapsulation of the remaining dataset that cannot be expressed natively in IFC which is bound in the <lifecycle > object, two alternative IFC integration approaches were realized in the interface normalization effort. The first approach defines an IfcLifecyle element as new entity in the IFC schema and adds the respectively needed features, as well as enables the above-mentioned elements to contain this element. The integration of life cycle data into the IFC as a profound basis to handle LCA-specific data offers more flexibility. In order to instantly ease an up-to-date enormous effort that is needed on the side of data collection to compile a LCA for a SBA and aggregating data for certification, a practicable interim approach based on native IFC 4 language is provided in addition to the general approach. Here, by defining a structured set of properties, and facilitating the given IFC concept of complex property sets, the needed LCA-specific dataset can be depicted using depiction methods already being supported by today's authoring systems. Without being able to provide the flexibility given through the underlying life cycle element conception of connecting these (alternative) IfcPropertySet objects to the different topological elements, in order to specify an elements LCA-related information, a similar approach defining static LCA property sets for building elements was pursued by Wastiels and Decuypere [16]. The IfcComplexProperties, as used in the interface presented in this paper, as an alternative depiction, have the advantage of providing the same structural facilities as needed by the developed life cycle elements blueprint, and therefore enable a simple conversion between the intermediate depiction as property set and the proposed extension of the IFC language with a (similarly structured) IfcLifecycle element. Hence, to get the IFC standard fit for the purpose of integrated LCA, as well as for the intermediate direct applicable form, two alternate integration paths are provided for normalizing the $<$ lifecycle $>$ object as developed from a LCA point-of-view based on the IFC standard.

The exemplary presented normalization of the LCA-specific data demands, as part of the IFC standard, is embedded in a principle of optional distributed (web-based) data to enhance the usability in ubiquitous real planning situations. Here, the web service developed by buildingSMART based on the data dictionary standard (ISO 12006-3) was taken as the base on which two services were realized to support the connection of LCA and planning data within the open BIM model. Hereby, the external reference object (derivation of the IfcReference object) given in the IFC was employed to specify a link to the classification reference that was hosted on a server developed within the research project. The classification was adopted from the framework of the Austrian FreeClass approach in order to better suit the German speaking region. In addition to synchronization to the material classification that is already in productive use, the developed standard-based contents of the server can be shifted to the existing service buidingSMART data dictionary (bsDD). Instead of every authoring system linking an IFC material object to its own web-based classification, this common facility enables a uniform "referential backbone" for connecting the LCA-specific data to the BIM model.

The IFC reference object on the other side can be used on top of the material classification link to further connect lifecycle objects, as described above, that are provided in a catalogue as demand oriented preconfigured datasets. In spite of adding all LCA information, especially during the dynamic early design stages, a corresponding reference in the BIM model already enables a comprehensive LCA detailing, for example, by pointing to the impact data of a certain construction type. While the concrete quantities are derived from the architectural model, the supplementary LCA specific information is provided on a uniform server that is reviewed by experts and can be adjusted to the cutting edge methodological and environmental impact data without changing the instance of the local BIM model referencing it. 
The process of defining the contents of the interface follows norm-based guidelines, as mentioned above and hence, all defined information demands collected in the extended IDM can be transferred in an MVD. Thereby, for instance, the IDM given in the Supplementary Material regarding the part of the life cycle element is matched with two alternative IFC depiction concepts, as detailed above. These allocations of IFC entities for the IDM table build the starting point for formalization of the intended standard-based interface. Then, by utilizing the MVD standard for specifying IFC model views, as a second step, the LCA information demands could be formally described as part of the IFC standard (an exemplary MVD excerpt regarding the abovementioned life cycle element in Supplementary Material 4). As a proposal for the creation of an official buildingSMART released MVD, the BIM2LCA MVD developed in the research project is inputted in the standardization work that is taking place for this thematic field in the Fachgruppe BIM und Nachhaltigkeit (working group BIM and sustainability) within the German buildingSMART chapter.

\subsection{Case Study}

In order to demonstrate the developed interface by transferring model-based data from the side of planning to the LCA tool GENERIS and further to the SBA, a BIM model of the Lernzentrum building on the KIT campus was modeled (Figure 11). The building that is owned by the state of Baden-Württemberg was constructed by the state office for property and construction in Baden-Württemberg (Vermögen und Bau Baden-Württemberg, VBW) in the framework of the Zukunft Campus project that aims at modernizing the KIT university campus. In addition to the main function of providing study places for students in the representative glass cube surrounding an atrium, it also hosts multipurpose auditorium and seminary rooms, as well as laboratories.

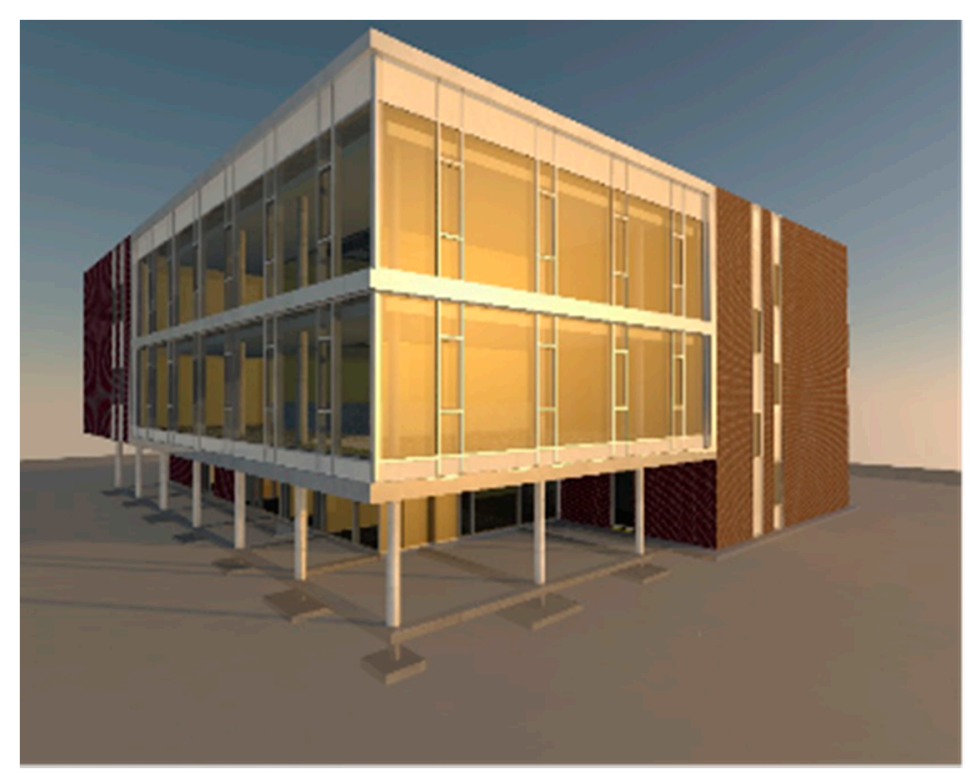

Figure 11. Building on the Karlsruhe Institute of Technology (KIT) campus used as evaluation model.

The BIM model was created in a common authoring software and from that exported into the open BIM standard ifcXML 4. The overall spatial structure (site, building, storey, and space), as well as common building elements (curtain/wall, slab, column, etc.) could, thereby, already be modeled. Furthermore, by modeling specialized decomposed building elements and using configured IFC profiles, the detailed topologies could also be exported to the IFC model, for example, the wall element shown in the FZK Viewer. Nevertheless, some shortcoming had to be handled in order to achieve the modeling quality needed as a base for the LCA-specific enhancements defined in the abovementioned model view. 
For the wall detailed with corresponding materials, in Figure 12, for instance, the redundant material objects for every single layer of every wall occurrence as created by the CAD system was unified to a type object. Hence, only one IfcWallType could be used for representing the common properties of all outer load-bearing walls with the same layers. This reduced the model redundancy and size. These type objects that also represented cost groups (according to DIN276) were referenced by the single wall instances in the model. On this further enhanced building information structure, the data requirements as input for the LCA tools could be added. For instance, the further decomposed single building component types of the wall element type were prepared with a link to a material object containing the classification reference object that referenced a specific material (e.g., concrete) in the external data dictionary, as described above. In addition to the reference object that points to a (generalized) type, and hence to this common material property, the occurrence of this concrete wall layer (see Figure 12) contained a specific quantity set that held the alphanumeric value of the volume. This was also represented in the geometry of the layer. These two base values then could be used with the LCA to determine the weight of the layer by taking into account the gross density property, which was also linked to the material.
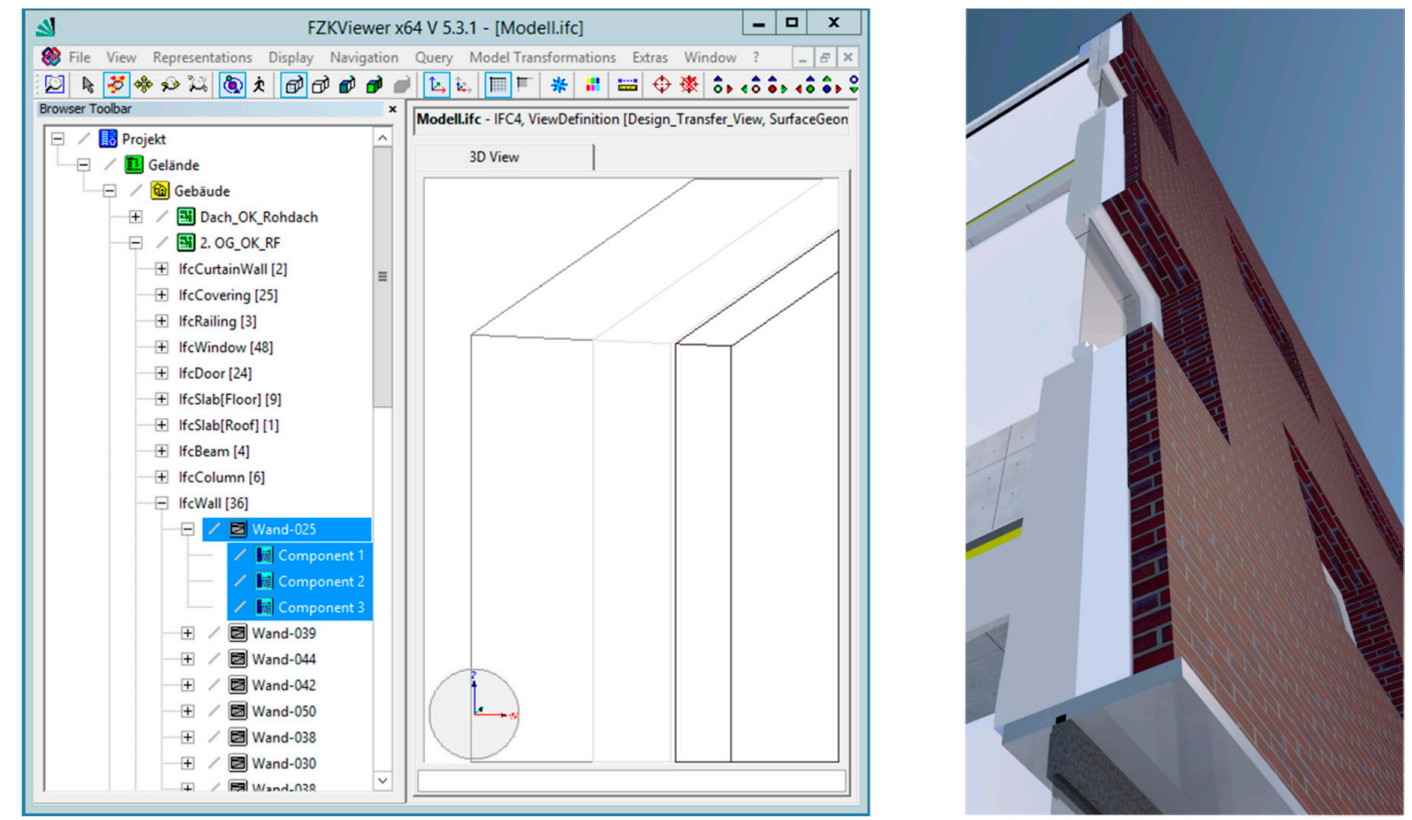

Figure 12. Data structure and BIM model of a section of outer load-bearing wall.

Table 1 lists an aggregated set of calculated values for the outer load-bearing walls on the first floor of the sample modeled building. With regard to these values, CAD platforms facilitate respective calculation functions, as they also are required for common model-based workflows, such as quantity take off. The ability to export these values into IFC quantity sets directly as needed as part of the BIM2LCA MVD is an innovative feature that, up to now, has only been supported by very few systems. The IFC file underlying the LCA calculation is provided in Supplementary Material 5.

Table 1. Quantity set of exemplary elements of load-bearing external walls on the first level.

\begin{tabular}{cccc}
\hline Construction Material & Layer Thickness $(\mathbf{m})$ & Layer Volume $\mathbf{( m}^{\mathbf{3}} \mathbf{)}$ & $\begin{array}{c}\text { Layer Area } \\
\left(\mathbf{m}^{\mathbf{2}} \mathbf{)}\right.\end{array}$ \\
\hline Facing brick masonry & 0.115 & 28.087 & 244.24 \\
\hline Vertical air layer & 0.01 & 2.499 & 249.89 \\
\hline $\begin{array}{c}\text { Insulation, expanded } \\
\text { polystyrene (EPS) rigid foam }\end{array}$ & 0.16 & 39.7805 & 248.86 \\
\hline Concrete, ferroconcrete C20/25 & 0.25 & 59.5095 & 238.04 \\
\hline
\end{tabular}


In order to support a wider range of currently available software, besides the advanced possibility in the MVD, to depict the aggregates coming from the designed geometries in quantity sets, storing them in the abovementioned layer sets that is still a more common IFC export feature is also permitted. Here, before calculating the weight, as indicated above, the volume of a layer needs to be calculated with its respectively given thickness and area (Table 1).

In the following example, The LCA calculation was carried out on behalf of a model-based data exchange from the planning side, i.e., BIM-based remodeling and modeling of a real building, as well as its optimization in order to fully comply with the defined specifications in the MVD, to the LCA tool GENERIS. Therefore, the calculation was based on the principal layers of the (massive) concrete external wall, insulation, and facing brick masonry (Figure 12 and Table 1 right side), with little alterations in the underground, ground, and roof levels.

The life cycle assessment of the given wall example provides an XML snippet based on the given XML schema structure in Supplementary Material 3. Figure 13 shows the underlying settings including all necessary meta-information to specify the underlying LCA. The life cycle element depicted in Figure 14 contains the core information on the LCA results. Given the material information in Table 1, there are still several ambiguities in the input data that require data enrichment and accordingly specification is need. The provided XML exemplifies this under specification through three scenarios. The base scenario SC1 makes use of the automatically mapped datasets from Ökobau.dat, which the LCA tool GENERIS provides. In SC2, the thermal conductivity of the EPS insulation (which is not specified in the model) is changed from $0.040 \mathrm{~W} / \mathrm{m} \cdot \mathrm{K}$ to $0.035 \mathrm{~W} / \mathrm{m} \cdot \mathrm{K}$, resulting in a different material and a different environmental impact dataset. The third scenario (SC3) overrides the standard end-of-life choices (which are the material specific scenarios) through a construction-related end-of-life, as a bulk deconstruction is assumed. The three scenarios do not cause any changes in the model, but display the specification options given though the LCA even when models are already relatively specific. The results can be fed back into the BIM model in the form of IFCXML.

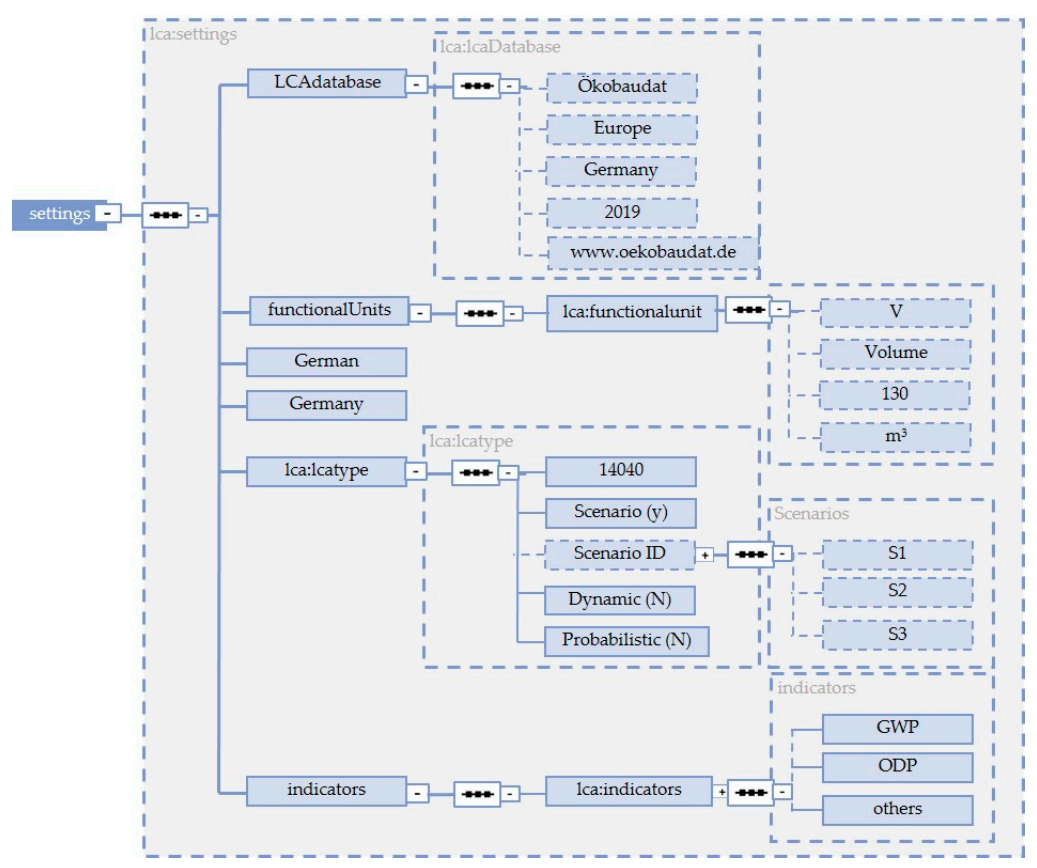

Figure 13. Exemplified LCA settings in the structure of the life cycle element, including the specification of the LCA database, the applied functional units, the LCA type, as well as the applied indicators. 


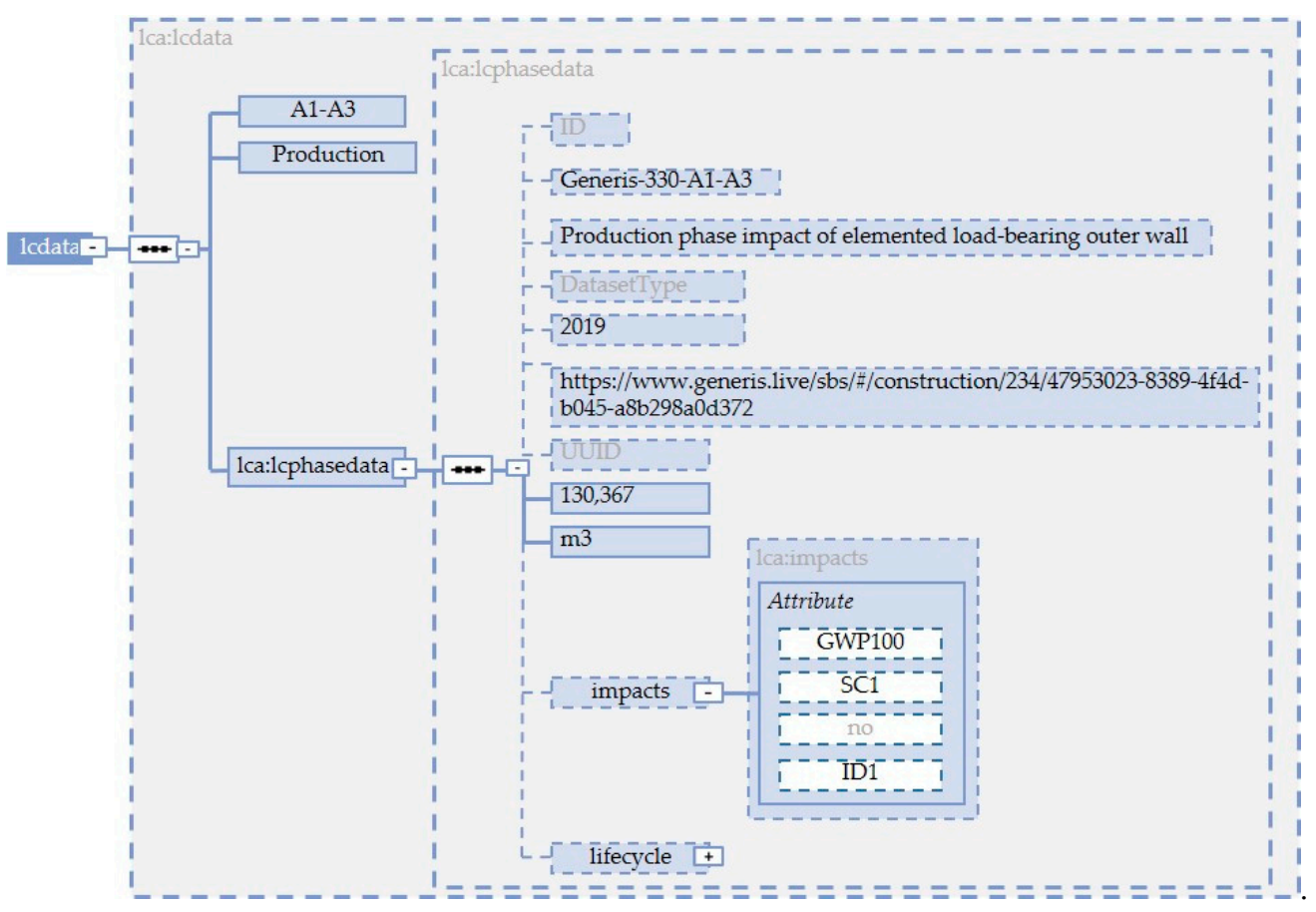

Figure 14. Exemplified results in the structure of the life cycle element provided for production phase, Global Warming Potential (GWP), and Scenario 1.

\section{Discussion}

The presented solution aims to set up an open and highly modular approach for the integration of BIM and LCA. This overall structure provides several advantages over current approaches. It builds upon the available standards and aims to be integrated in these. Through the standardization process the proposed solution is assumed to be critically evaluated and thus improved. However, the standard integration will hinder a fast application of the approach, as standardization processes oftentimes take years to complete.

As for the XSD, changes and enrichment of the IDM are possible depending on the SBA tool and building certification. The realized data structure allows more automatized submission processes, exemplarily realized within the novel SBA tool GENERIS®and DGNB certification system. For this reason, the technical specification of the data structure and contents follows the software architecture, and the definition of a three-level hierarchical structure (project, constructions, and layers). Aside from the LCA element, two further elements gather data and metadata for a building environmental certification. In this regard, the XSD currently represents a specific solution for the German DGNB. However, thanks to the flexibility of the LCA project element, the XSD can be easily modified and extended for other submissions to certification systems. With regard to the LCA project, the life cycle element is characterized by an open, flexible, and extendable structure. In fact, even at the most detailed material level, the BIM2LCA user can define undetermined levels for the LCA analysis, by entering more and more detailed life cycle information. Furthermore, life cycle element is present at higher construction and project levels, which enables analyses of a grouping of LCA results. Consequently, the object can easily be adapted for all SBA tools and BIM environments.

Together with its contents, in the XSD, it is possible to extend the LCA analysis approaches. In fact, in a first instance, quantities can be entered not only in the form of single values, but also in matrices for a scenario analysis. Furthermore, LCA results can be presented in the form of values matrices, by enabling dynamic and even probabilistic analyses. This last representation of results is particularly advantageous for the integration of environmental benchmarks, whereas the interface is used as an instrument to support decision making during the early planning stages. Lastly, the element can proceed processes belonging to different environmental databases and more indicators systems, 
by assigning the database specifications and the LCA methodology. From a technical point-of-view, there are still open issues. The interface is not yet applicable in closed BIM environments due to their delayed implementation of IFC standards; in addition, in open BIM the implementation in standardized IFC seems to be still challenging and will require more efforts in terms of cooperation among software developers, as well as BIM and LCA experts.

As research on digitalization in the building sector and life cycle assessment receives more attention, the established approach and its respective interface should be further developed aiming at robust LCA integration. Among others, the interface should be adapted to incorporate predictive life cycle assessment. As a result, the new derived interface should support environmental decisions within product development, building and construction processes, as well as the building operation phase; making possible more robust statements in the early design stage under limited information basis and uncertain boundary conditions, for example, by provision of benchmarks and statistical records. Finally, the interconnectivity among building models and SBA tools should be improved to enable explorative design computations and real-time decision support regarding environmental aspects for continuous optimization of variants and alternatives.

\section{Conclusions}

This work presents the BIM2LCA approach with the technical implementation of a BIM-LCA interface through an XSD data structure for the compilation and the submission of the final XML. The IDM is the basis and guideline for the development of a standardized BIM-LCA interface, here, presented in the form of a table according to ISO 29481-1:2010. The specification and the following classification of object characteristics define a standardized and automatized planning process, in which actors enter specific information in a defined design phase. In this work, we particularly investigated how the information availability and demand throughout the planning process can be considered. This has consequences on the information demand for the LCA over the planning and building life cycle. In addition, it demonstrates the multitude of information to be handled, which is a relevant issue of the integral planning which leads to high efforts during the IDM technical realization. In general, the proposed workflow offers a strategy that goes beyond available approaches, however, it requires a complex setup which is not yet directly applicable in existing BIM environments. The realization of the presented approach in a fully mature planning phase integrated open workflow requires further consolidation, extensive testing, and harmonization of the proposed approach and the adjustment of standardized methods such as IFC with regard to the technical requirements derived from it.

The presented approach aims to trigger discussion and proposes possible solutions and outlooks for the integration of LCA in the dynamically digitalizing integrated planning processes in a context where more attention on the sustainability of buildings is urgently required. While some specific closed BIM solutions exist that couple BIM and LCA, we present the first open and fully modular and extendible approach. Thus, we propose this approach as a basis for discussion and development that aims for standard integration and creates the opportunity for real broad scale LCA integration in digital planning and construction.

Supplementary Materials: The following are available online at http:/www.mdpi.com/2071-1050/12/16/6558/ s1, Supplementary Material 1: Process map for BIM2LCA (bpmn), Supplementary Material 2: Information requirements for BIM2LCA (xlsx), Supplementary Material 3: XML schema definition for LCA submitted to DGNB for certification (XSD), Supplementary Material 4: e`Exemplary MVD excerpt (mvd), Supplementary Material 5: Case study ifcxml (IFCXML), Supplementary Material 6: LCA case study results (XML).

Author Contributions: P.v.B. acquired the funding; R.H. and S.E. coordinated the underlying scientific project; P.v.B., R.H. and S.E. structured the manuscript; R.H. harmonized and finalized the manuscript; Section 1, P.v.B., S.E., and R.H.; Section 2, P.v.B., O.J., R.D.B., S.E., and R.H. Section 3, R.D.B., S.E., and R.H.; Section 4, R.D.B. and R.H.; Section 5, R.D.B. and R.H.; Supplementary Material 1, O.J., R.T., R.D.B., and R.H.; Supplementary Material 2, S.E.; Supplementary Material 3, O.J., R.T., R.D.B., S.E., and R.H.; Supplementary Material 4, R.D.B. and R.H. All authors have read and agreed to the published version of the manuscript.

Funding: The publication, as well as the therein-presented methods and results, have been created within the research project BIM2LCA4IP and are funded by the German Federal Ministry for Economic Affairs and Energy 
BMWi. This publication has been supported by the Deutsche Forschungsgemeinschaft (DFG, German Research Foundation) under Germany's Excellence Strategy, -EXC 2120/1 -390831618. We acknowledge support by the KIT-Publication Fund of the Karlsruhe Institute of Technology.

Conflicts of Interest: The authors declare no conflict of interest.

\section{Abbreviations}

\begin{tabular}{|c|c|}
\hline (e)BNB & (elektronisches) Bewertungssystem Nachhaltiges Bauen \\
\hline AIA & Auftraggeberinformationsanforderungen \\
\hline BBSR & Bundesinstitut für Bau-, Stadt- und Raumforschung \\
\hline BCF & BIM Collaboration Format \\
\hline BEP & BIM execution plan \\
\hline BIM & Building information modeling \\
\hline BMWi & Bundesministerium für Wirtschaft und Energie \\
\hline BPMN & Business process management notation \\
\hline BPS & Building performance simulation \\
\hline bsDD & BuildingSMART data dictionary \\
\hline DGNB & Deutsche Gesellschaft für nachhaltiges Bauen \\
\hline DIN & Deutsches Institut für Normung \\
\hline EPD & Environmental Product Declaration \\
\hline EPS & Expanded polystyrene \\
\hline FZK & Forschungszentrum Karlsruhe \\
\hline GENERIS & Software name (www.generis.live) \\
\hline gbXML & Green building XML format \\
\hline GWP & Global Warming Potential \\
\hline IBP & Fraunhofer Institute for Building Physics \\
\hline IDM & Information delivery manual \\
\hline IFC & Industry Foundation Classes \\
\hline IFCXML & XML variant of the IFC standard \\
\hline IP & Integral planning \\
\hline KIT & Karlsruhe Institute of Technology \\
\hline LCA & Life cycle assessment \\
\hline LCC & Life cycle costing \\
\hline LCIA & Life cycle impact assessment \\
\hline LOD & Level of development \\
\hline MVD & Model view definition \\
\hline PEF & Indicators EN15898 \\
\hline SBA & Sustainable building assessment \\
\hline sbs & Software name (www.sbs-onlinetool.com) \\
\hline SC & Scenario \\
\hline VBW & Vermögen und Bau Baden-Württemberg \\
\hline XML & Extensible markup language \\
\hline XSD & XML schema definition \\
\hline
\end{tabular}

\section{References}

1. Gantner, J.; Wittstock, B.; Lenz, K.; Fischer, M.; Sedlbauer, K.; Anderson, J.; Saunders, T.; Gyetvai, Z.; Carter, C.; Braune, A.; et al. EeBGuide Guidance Document Part B: Buildings; Fraunhofer Verlag: Stuttgart, Germany, 2015.

2. Di Bari, R.; Jorgji, O.; Horn, R.; Gantner, J.; Ebertshäuser, S. Step-by-step implementation of BIM-LCA: A case study analysis associating defined construction phases with their respective environmental impacts. IOP Conf. Ser. Earth Environ. Sci. 2019, 323, 12105. [CrossRef]

3. Bundesministerium für Wirtschaft und Energie (BMWi). Energieforschungsprogramm der Bundesregierung: Innovationen für die Energiewende; Bundesministerium für Wirtschaft und Energie (BMWi) Öffentlichkeitsarbeit: Berlin, Germany, 2018; Available online: https://www.bmwi.de/Redaktion/DE/Publikationen/ Energie/7-energieforschungsprogramm-der-bundesregierung.pdf?_blob=publicationFile\&v=14 (accessed on 14 May 2019).

4. European Commission. The European Green Deal: Communication from the Commission to the European Parliament, the European Council, the Council, the European Economic and Social Committee and the Committee of the Regions; the European Commission: Brussels, Belgium, 2019.

5. International Energy Agency. IEA EBC Annex 72, Assessing Life Cycle Related Environmental Impacts Caused by Buildings. Energy in Buildings and Communities Programme (EBC). Available online: http: //annex72.iea-ebc.org/ (accessed on 7 June 2018). 
6. International Energy Agency. I.E.A. Digitalization and Energy; IEA: Paris, France, 2017.

7. Lasveaux, S.; Gantner, J.; Schiopu, N.; Nibel, S.; Bazzana, M.; Bosdevigie, B.; Sibiude, G. Towards a new generation of building LCA tools adapted to the building design process and to the user needs? In Sustainable Buildings-Construction Products E Technologies, Proceedings of the Sustainable Building Conference 2013, Graz University of Technology, Graz, Austria, 25-28 September 2013; Höfler, K., Maydl, P., Passer, A., Eds.; Verlag der Technischen Universität Graz: Graz, Austria, 2013.

8. Lambertz, M.; Theißen, S.; Höper, J.; Wimmer, R.; Meins-Becker, A.; Zibell, M. Ökobilanzierung und BIM im Nachhaltigen Bauen: Endbericht; Bundesinstitut für Bau-, Stadt- und Raumforschung (BBSR) im Bundesamt für Bauwesen und Raumwesen (BBR): Berlin, Germany, 2020.

9. Zimmermann, K. Anwendung des Leitfadens Nachhaltiges Bauen und des Bewertungssystems Nachhaltiges Bauen (BNB) in den Bundesbauverwaltungen: Zusatzmodul Lebenszyklusanalysen nach BNB; Ökobilanzierung (LCA): Hamm, Germany, 2012.

10. Chong, H.-Y.; Lee, C.-Y.; Wang, X. A mixed review of the adoption of Building Information Modelling (BIM) for sustainability. J. Clean. Prod. 2017, 142, 4114-4126. [CrossRef]

11. Gomes, V.; Barros, N.N.; Ruschel, R.C. Building Information Modelling for Whole-Building LCA: BIM4LCA. IOP Conf. Ser. Earth Environ. Sci. 2019, 290, 12044. [CrossRef]

12. Santos, R.; Costa, A.A.; Silvestre, J.D.; Pyl, L. Integration of LCA and LCC analysis within a BIM-based environment. Autom. Constr. 2019, 103, 127-149. [CrossRef]

13. Deng, Y.; Cheng, J.C.P.; Anumba, C. Mapping between BIM and 3D GIS in different levels of detail using schema mediation and instance comparison. Autom. Constr. 2016, 67, 1-21. [CrossRef]

14. Hollberg, A.; Genova, G.; Habert, G. Evaluation of BIM-based LCA results for building design. Autom. Constr. 2020, 109, 102972. [CrossRef]

15. Cavalliere, C.; Dell'Osso, G.R.; Pierucci, A.; Iannone, F. Life cycle assessment data structure for building information modelling. J. Clean. Prod. 2018, 199, 193-204. [CrossRef]

16. Wastiels, L.; Decuypere, R. Identification and comparison of LCA-BIM integration strategies. IOP Conf. Ser. Earth Environ. Sci. 2019, 323, 12101. [CrossRef]

17. Obrecht, P.T.; Röck, M.; Hoxha, E.; Passer, A. BIM and LCA Integration: A Systematic Literature Review. Sustainability 2020, 12, 5534. [CrossRef]

18. Schwaninger, M. Integrale Planung: Ein innovatives Konzept? Die Unternehm. 1988, 42, 123-136.

19. Rexroth, K.; von Both, P. Integrale Planung: Merkmale zur Identifizierung und Initialisierung in der kommunalen Praxis. In REAL CORP 2017 PANTA RHEI-A World in Constant Motion, Proceedings of the 22nd International Conference on Urban Planning, Regional Development and Information Society, Tagungsband, Vienna, Austria, 12-14 September 2017; Schrenk, M., Ed.; CORP: Wien, Austria, 2017.

20. Rexroth, K.; von Both, P.; Gantner, J.; Schmid, C. Ein Ansatz für die typologiebasierte Vervollständigung von Gebäudeinformationen zur Unterstützung der frühen Planungsphasen am Beispiel LCA; KIT: Karlsruhe, Germany, 2018. [CrossRef]

21. Borrmann, A.; Elixmann, R.; Eschenbruch, K.; Forster, C.; Hausknecht, K.; Hecker, D.; Hochmuth, M.; Klempin, C.; Kluge, M.; König, M.; et al. Leitfaden und Muster für Auftraggeber-Informationsanforderungen (AIA): Handreichungen und Leitfäden-Teil 2; Bundesministerium für Verkehr und digitale Infrastruktur (BMVI): Berlin, Germany, 2019.

22. Rheinland, T.Ü. Bundesministerium für Verkehr und digitale Infrastruktur (BMVI). In Stufenplan Digitales Planen und Bauen: Einführung moderner, IT-gestützter Prozesse und Technologien bei Planung, Bau und Betrieb von Bauwerken; Bundesministerium für Verkehr und digitale Infrastruktur (BMVI): Berlin, Germany, 2015.

23. Beetz, J.; Borrmann, A.; Weise, M. Prozessgestützte Defintion von Modellinhalten; Springer: Wiesbaden, Germany, 2015.

24. von Both, P. Aktuelle Ansätze zur Unterstützung interdisziplinärer Zusammenarbeit im Bauwesen. In Wissenschaft im Kontext: Inter-und Transdisziplinarität in Theorie und Praxis, 1st ed.; Banse, G., Ed.; Trafo-Wiss.-Verl.: Berlin, Germany, 2011; Volume 27, pp. 227-242.

25. von Both, P.; Ebertshäuser, S. BIM-basierte Hilfsmittel für eine integrale Planung. In Construction Goes Digital: Chancen, Risiken, Nutzen: Praxisreport 2017; Achammer, C.M., Kovacic, I., Eds.; Klein Publishing GmbH: Vienna, Austria, 2018. 
26. von Both, P. Integrale Planung und BIM. In Building Information Modeling Management: Methoden und Strategien für den Planungsprozess, Beispiele aus der Praxis; Herrmann, E., Westphal, T., Eds.; DETAIL: München, Germany, 2015.

27. Remmen, P.; Cao, J.; Ebertshäuser, S.; Frisch, J.; Lauster, M.; Maile, T.; Müller, D.; van Treeck, C. An open framework for integrated BIM-based building performance simulation using Modelica. In Proceedings of the 14th International Conference of the International Building Performance Simulation Association (IBPSA), BS2015, no. 2384, Hyderabad, India, 7-9 December 2015; Available online: http://www.ibpsa.org/ proceedings/BS2015/p2384.pdf (accessed on 23 January 2018).

28. Ebertshäuser, S.; von Both, P. Standardized Representation of Typological Data as Common Input for Urban Performance Simulation. In Proceedings of the Building Simulation 2019: 16th Conference of IBPSA, Rome, Italy, 2-4 September 2019; Corrado, V., Gasparella, A., Eds.; International Building Performance Association IBPSA: Rome, Italy, 2019. ISBN 978-1-7750520-1-2.

29. Ebertshäuser, S.; von Both, P.; Brüggemann, T.; Ochse, S.; Lauster, M.; Malhotra, A.; Frisch, J.; Remmen, P.; Müller, D.; van Treeck, C. Unterstützung kommunalplanerischer Prozesse mit CityGML-basierter Anbindung Modelica-betriebener Quartierssimulation. In BauSIM 2018; von Both, P., Wagner, A., Eds.; KIT: Karlsruhe, Germany, 2018.

30. Nilsen, M.; Bohne, R.A. Evaluation of BIM based LCA in early design phase (low LOD) of buildings. IOP Conf. Ser. Earth Environ. Sci. 2019, 323, 12119. [CrossRef]

31. Gantner, J. Wahrscheinlichkeitsbasierte Ökobilanzierung zur Berücksichtigung von Unsicherheiten in zukünftigen Entscheidungen und Ereignissen; Fraunhofer-Informationszentrum Raum und Bau IRB: Stuttgart, Germany, 2018.

32. Gantner, J.; von Both, P.; Rexroth, K.; Ebertshäuser, S.; Horn, R.; Jorgji, O.; Schmid, C.; Fischer, M. Ökobilanz-Integration in den Entwurfsprozess: BIM-basierte entwurfsbegleitende Ökobilanz in frühen Phasen einer Integralen Gebäudeplanung; Bauphysik: Berlin, Germany, 2018.

33. Ebertshäuser, S.; Graf, K.; von Both, P.; Rexroth, K.; Di Bari, R.; Horn, R. Sustainable building information modeling in the context of model-based integral planning. IOP Conf. Ser. Earth Environ. Sci. 2019, 323, 12113. [CrossRef]

34. Kaufhold, M. BIM in Zahlen-Status Quo. In BIM-Building Information Modeling: Management Band 2; Digitale Planungswerkzeuge in der interdisziplinären, Anwendung; Herrmann, E., Westphal, T., Eds.; Edition DETAIL-DETAIL Business Information GmbH: München, Germany, 2017; pp. 6-14.

35. von Both, P.; Koch, V.; Kindsvater, A. BIM-Potentiale, Hemmnisse und Handlungsplan (BIM-Potentials, Barriers and Roadmap): Analyse der Potentiale und Hemmnisse bei der Umsetzung der Integrierten Planungsmethodik Building Information Modeling-BIM-in der deutschen Baubranche und Ableitung eines Handlungsplanes zur Verbesserung der Wettbewerbssituation (Analysis of Potentials and Obstacles in the Implementation of the Integrated Planning Methodology Building Information Modeling-BIM-in the German Construction Industry and Derivation of an Roadmap to Improve the Competitive Situation); Forschungsvorhaben F2844; Fraunhofer IRB Verlag: Stuttgart, Germany, 2013.

36. Building SMART International. What Is Open BIM®? Available online: https://www.buildingsmart.org/ about/openbim/openbim-definition/ (accessed on 8 June 2020).

37. Westphal, T. Open vs. Closed BIM. Was lohnt sich für mich? In Verschiedene Ansätze zur Zusammenarbeit in der Gebäudeplanung; DBZ: Gütersloh, Germany, 2018.

38. International Organization for Standardization (ISO) ISO 29481-1. Building Information Models-Information Delivery Manual-Part 1: Methodology and Format 2016; 2016, 91.010.01. Available online: https: //www.iso.org/standard/51622.html.05-2016 (accessed on 22 July 2017).

39. Verein Deutscher Ingenieure e.V. (VDI). Richtlinienreihe VDI 2552 "Building Information Modeling (BIM)" (Series VDI 2552 "Building Information Modeling (BIM)"), VDI-Fachbereich Technische Gebäudeausrüstung (VDI Department of Building Services Engineering), 2017-2018. Available online: https://www.vdi.de/technik/fachthemen/bauen-und-gebaeudetechnik/fachbereiche/bautechnik/richtlinien/ richtlinienreihe-vdi-2552-building-information-modeling/ (accessed on 3 July 2018).

40. International Organization for Standardization 14040. Environmental Management-Life Cycle Assessment-Principles and Framework; ISO: Geneva, Switzerland, 2006.

41. International Organization for Standardization 14044. Environmental management-Life Cycle Assessment-Requirements and Guidelines; ISO: Geneva, Switzerland, 2006. 
42. Deutsches Institut für Normung E.V. (DIN)-German Institute for Standardization (DIN) DIN EN 15804 (EN 15804:2012+A1:2013/prA2:2018). Nachhaltigkeit von Bauwerken (Sustainability of Construction Works)_Umweltproduktdeklarationen (Environmental Product Declarations)_Grundregeln für die Produktkategorie Bauprodukte (Core Rules for the Product Category of Construction Products); Beuth: Berlin, Germany, 2018; Available online: https://www.beuth.de/de/norm-entwurf/din-en-15804-a2/283026323 (accessed on 7 June 2018).

43. Deutsches Institut für Normung E.V. (DIN)-German Institute for Standardization (DIN) DIN V 18599-1. Energetische Bewertung von Gebäuden-Berechnung des Nutz, End-und Primärenergiebedarfs für Heizung, Kühlung, Lüftung, Trinkwarmwasser und Beleuchtung-Teil 1: Allgemeine Bilanzierungsverfahren, Begriffe, Zonierung und Bewertung der Energieträger (Energy Efficiency of Buildings-Calculation of the Net, Final and Primary Energy Demand for Heating, Cooling, Ventilation, Domestic Hot Water and Lighting-Part 1: General Balancing Procedures, Terms and Definitions, Zoning and Evaluation of Energy Sources); Beuth Verlag GmbH: Berlin, Germany, 2016; Available online: https:/www.beuth.de/de/vornorm/din-v-18599-1/257938824 (accessed on 25 June 2018).

44. Gantner, J.; Lenz, K.; Horn, R.; von Both, P.; Ebertshäuser, S. Ökobau.dat 3.0-Quo Vadis? Buildings 2018, 8, 129. [CrossRef]

45. Bauer, M.; Mösle, P.; Schwarz, M. Green Building: Leitfaden für Nachhaltiges Bauen, 2nd ed.; Springer: Berlin, Germany, 2013.

46. European Union. LEVEL(S): Taking Action on the TOTAL Impact of the Construction Sector; European Union: Luxembourg, 2019.

47. European Commission. Review Report of the Environmental Footprint Pilot Phase. Available online: http://ec.europa.eu/environment/eussd/smgp/pdf/2017_peer_rev_finrep.pdf (accessed on 26 June 2020).

48. Röck, M.; Hollberg, A.; Habert, G.; Passer, A. LCA and BIM: Integrated Assessment and Visualization of Building Elements' Embodied Impacts for Design Guidance in Early Stages. Procedia CIRP 2018, 69, $218-223$. [CrossRef]

49. Frischknecht, R.; Wyss, F.; Knöpfel, S.B.; Stolz, P. Life cycle assessment in the building sector: Analytical tools, environmental information and labels. Int. J. Life Cycle Assess 2015, 20, 421-425. [CrossRef]

50. Meex, E.; Hollberg, A.; Knapen, E.; Hildebrand, L.; Verbeeck, G. Requirements for applying LCA-based environmental impact assessment tools in the early stages of building design. Build. Environ. 2018, 133, 228-236. [CrossRef]

51. Huovila, P.; Hyvärinen, J.; Palos, S.; Rekola, M.; Chevalier, J.; Fiès, B.; Lebègue, E. Linking SBA Metrics to IFCs and BIM: Final Report. Build. Inf. Model. Environ. Indic. 2012, 78, 2012.

52. Antón, L.Á.; Díaz, J. Integration of Life Cycle Assessment in a BIM Environment. Procedia Eng. 2014, 85, 26-32. [CrossRef]

53. Cavalliere, C.; Hollberg, A.; Dell'Osso, G.R.; Habert, G. Consistent BIM-led LCA during the entire building design process. IOP Conf. Ser. Earth Environ. Sci. 2019, 323, 12099. [CrossRef]

54. Building Research Establishment Ltd. About BIM. Available online: https://www.bre.co.uk/page.jsp?id=3445 (accessed on 25 July 2020).

55. Caala GmbH. CAALA. Ihr digitaler Assistent für ganzheitliches Entwerfen. Available online: https://caala.de/ (accessed on 25 July 2020).

56. Fraunhofer Institute for Building Physics (IBP). GENERIS ${ }^{\circledR}$. Available online: https://generis.live (accessed on 25 July 2020).

57. Bundesministerium des Innern, für Bau und Heimat (BMI). Nutzungsdauern von Bauteilen für Lebenszyklusanalysen nach Bewertungssystem Nachhaltiges Bauen (BNB): Useful Service Lives of Building Construction Components According to the Sustainable Building Assessment System BNB; Bundesministerium des Innern, für Bau und Heimat (BMI): Berlin, Germany, 2017.

58. de Wilde, P.; Mahdjoubi, L.; Galiano, A. (Eds.) Building Information Modelling (BIM) in Design, Construction and Operations III; WIT Press: Southampton, UK, 2019.

(C) 2020 by the authors. Licensee MDPI, Basel, Switzerland. This article is an open access article distributed under the terms and conditions of the Creative Commons Attribution (CC BY) license (http://creativecommons.org/licenses/by/4.0/). 